Supporting Information:

\title{
Stereocontrolled [4+2]-Annulation Accessing Dihyrdopyrans: Synthesis of the C1a-C10 Fragment of Kendomycin
}

\author{
Jason T. Lowe and James S. Panek* \\ Department of Chemistry \\ Center for Chemical Methodology and Library Development \\ 590 Commonwealth Avenue, Boston University, \\ Boston, Massachusetts 02215
}

\section{${ }^{1} \mathrm{H} \&{ }^{13} \mathrm{C}$ NMR}




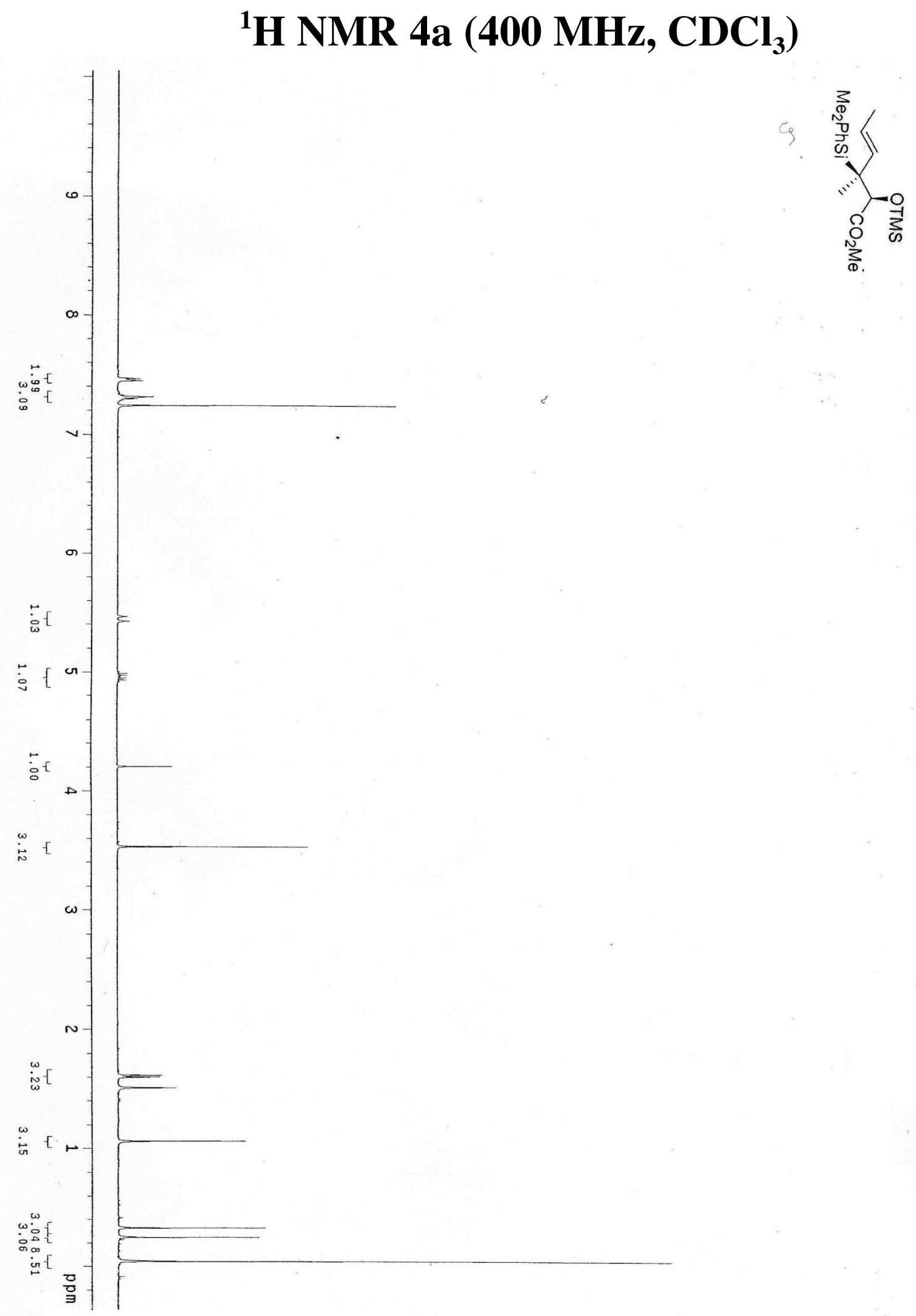

SI - 2 


\section{${ }^{13} \mathrm{C}$ NMR 4a (400 MHz, $\left.\mathrm{CDCl}_{3}\right)$}

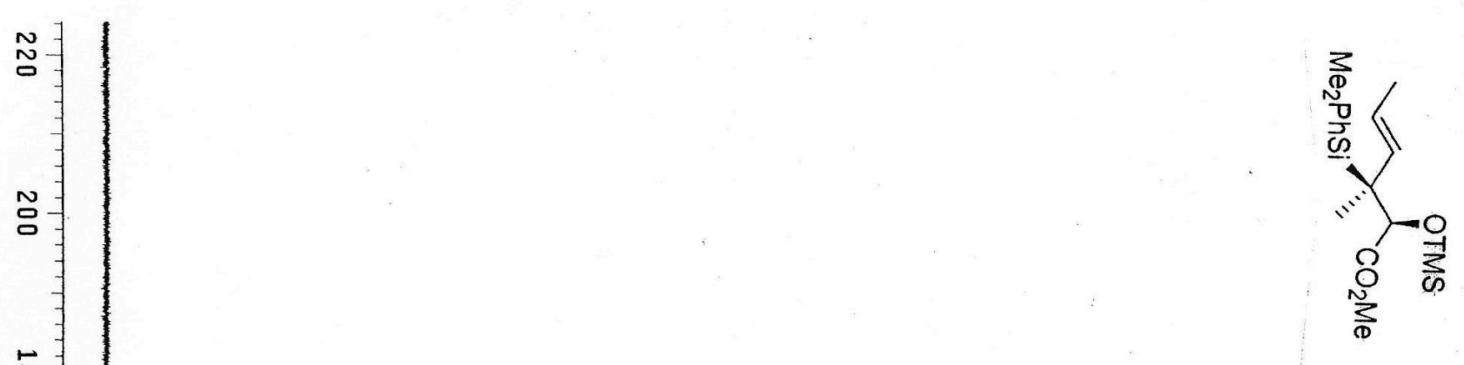

$\stackrel{\circ}{\circ}$

몽

点

$\stackrel{5}{N}$

宫

$\infty$

g

B

ำ

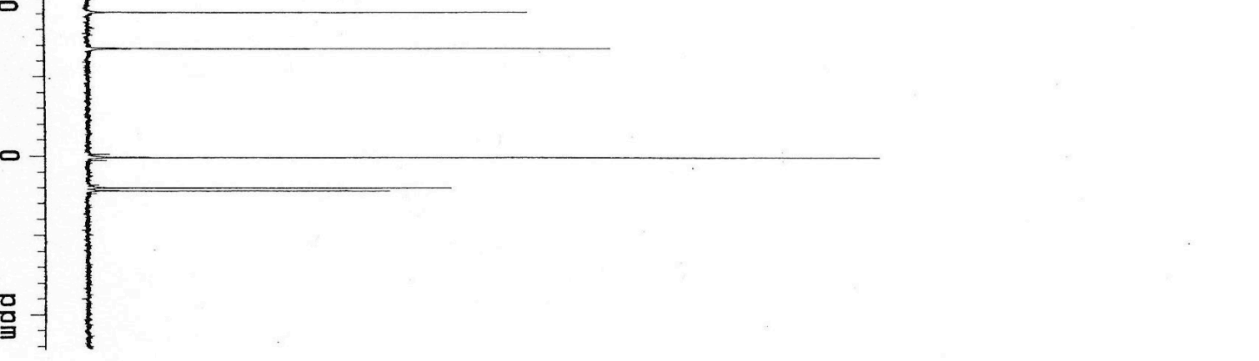

SI - 3 


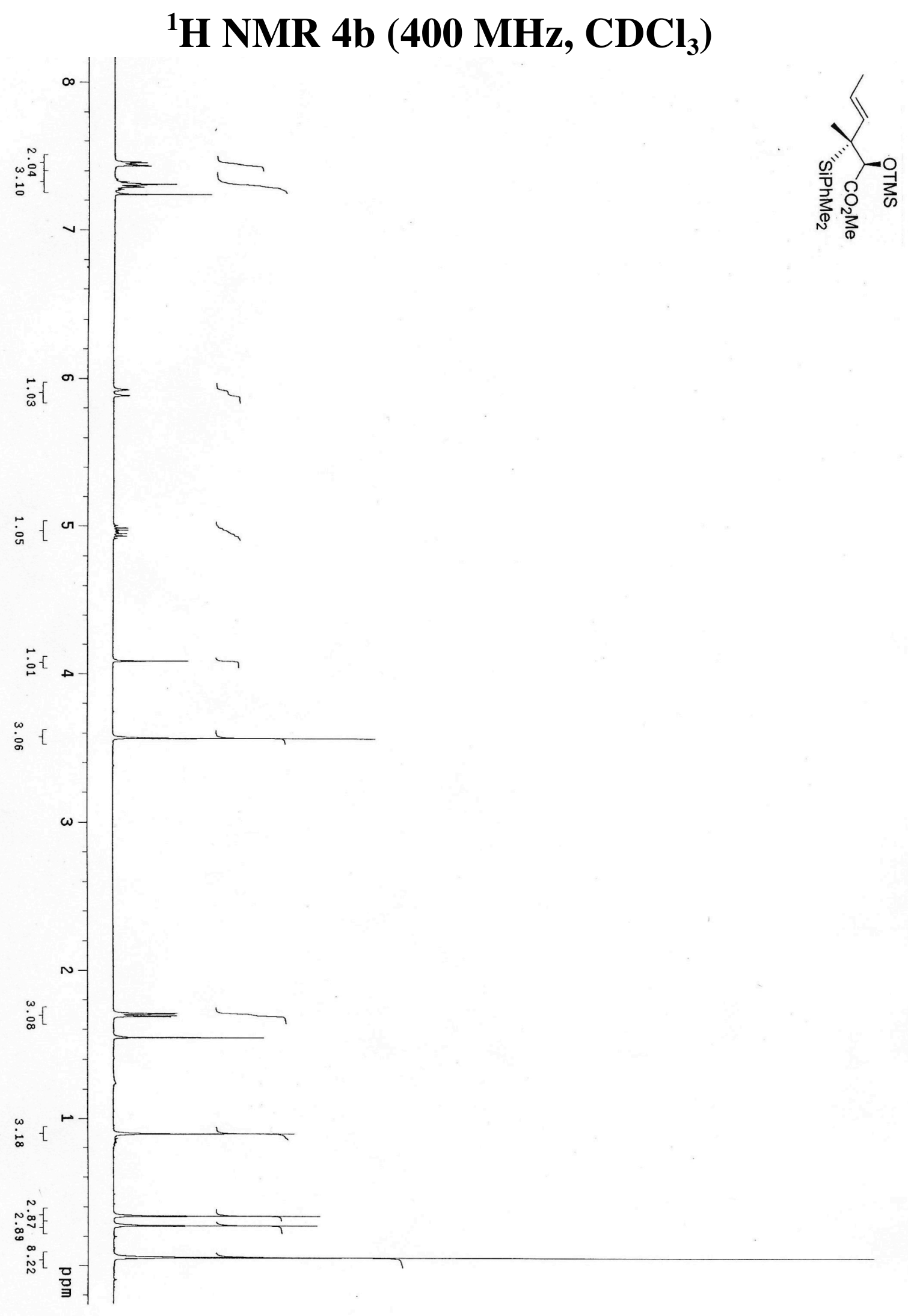

SI - 4 


\section{${ }^{13} \mathrm{C}$ NMR 4b (400 MHz, $\left.\mathrm{CDCl}_{3}\right)$}

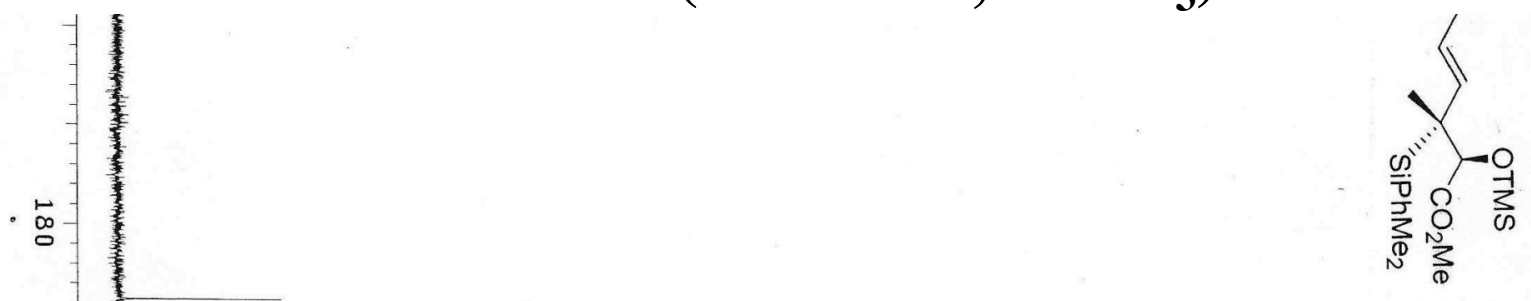

홍

$\stackrel{b}{a}$

o.

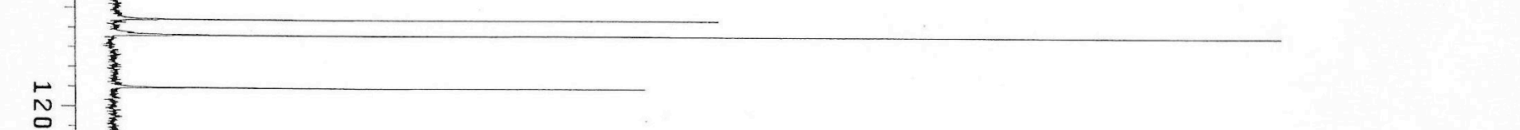

N

.

. 옹

$\stackrel{\infty}{\circ-1}$

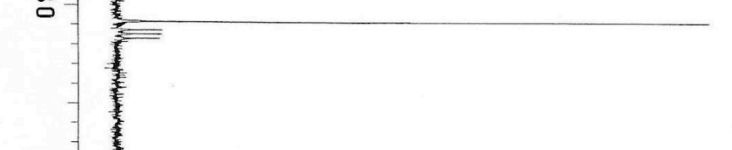

용

再

号-

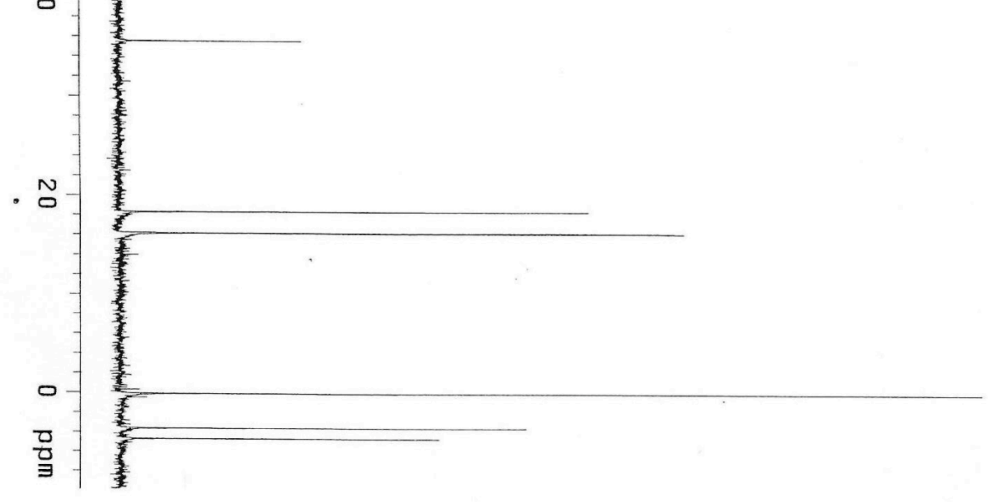

SI - 5 

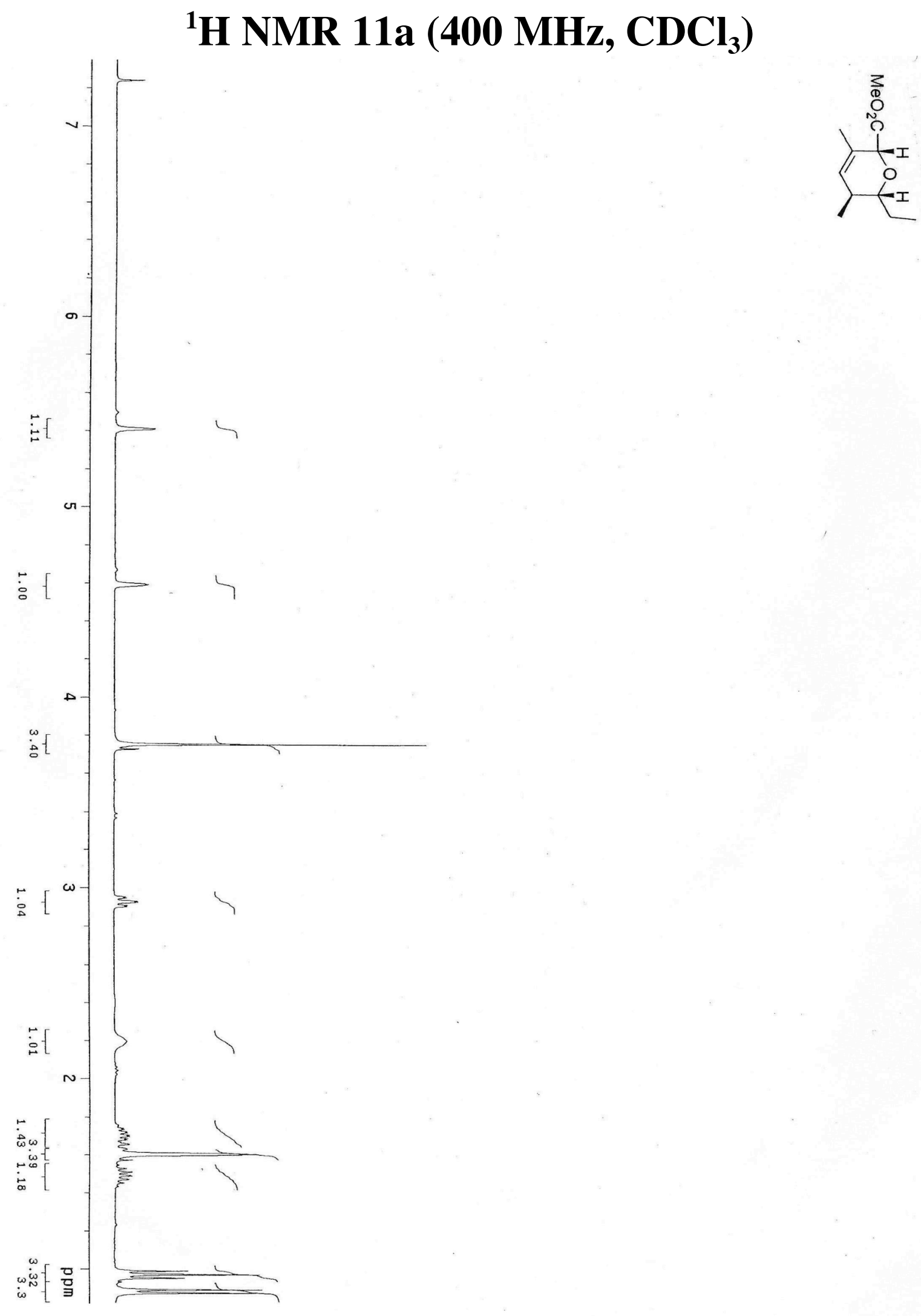


\section{${ }^{13}$ C NMR 11a (400 MHz, $\mathrm{CDCl}_{3}$ )}

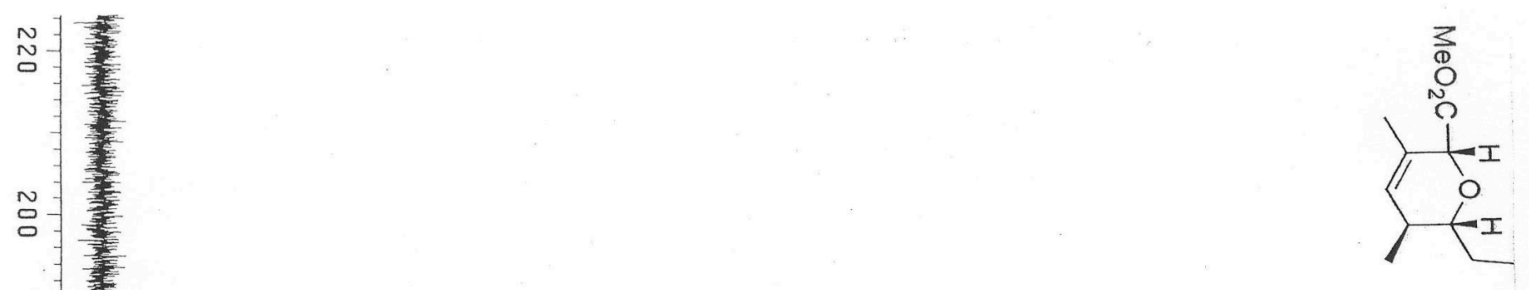

$\stackrel{\circ}{\circ}$

뭉

$\stackrel{\square}{\circ}$

N.

-

旁

:

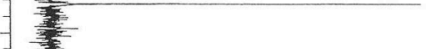

N-

.

再

$\circ-$

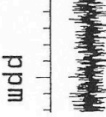

SI - 7 


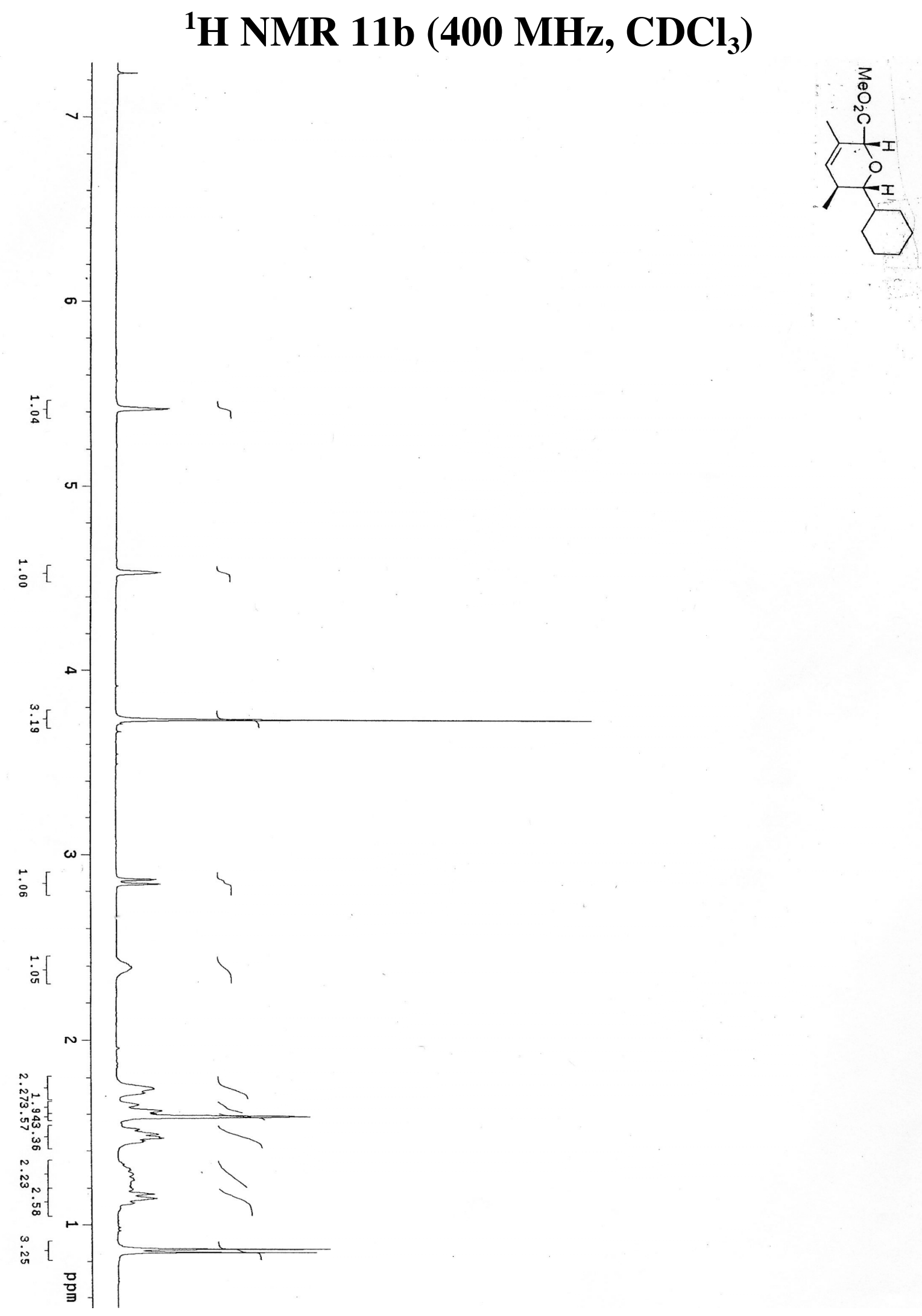

SI - 8 


\section{${ }^{13} \mathrm{C}$ NMR 11b (400 MHz, $\left.\mathrm{CDCl}_{3}\right)$}
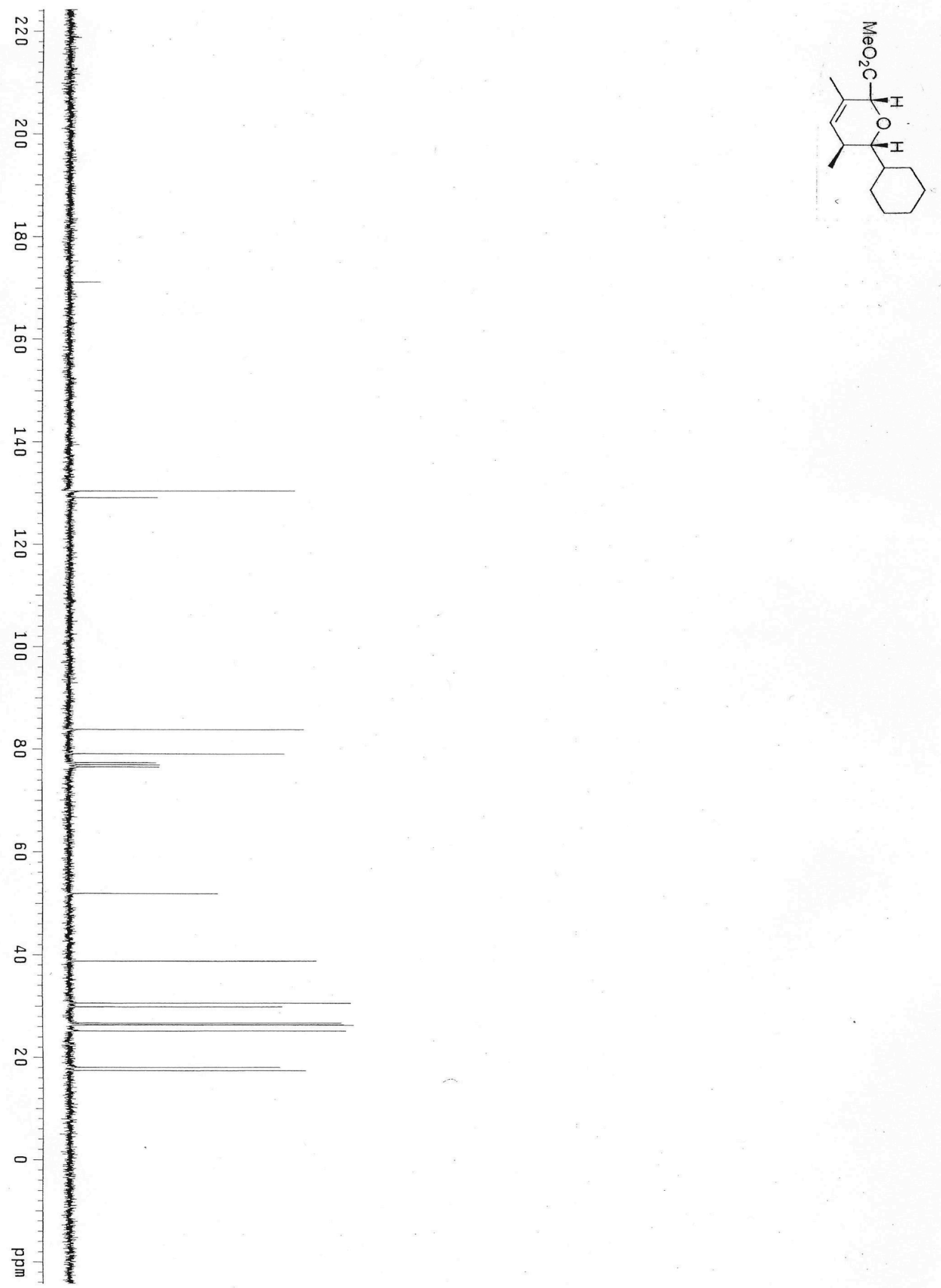


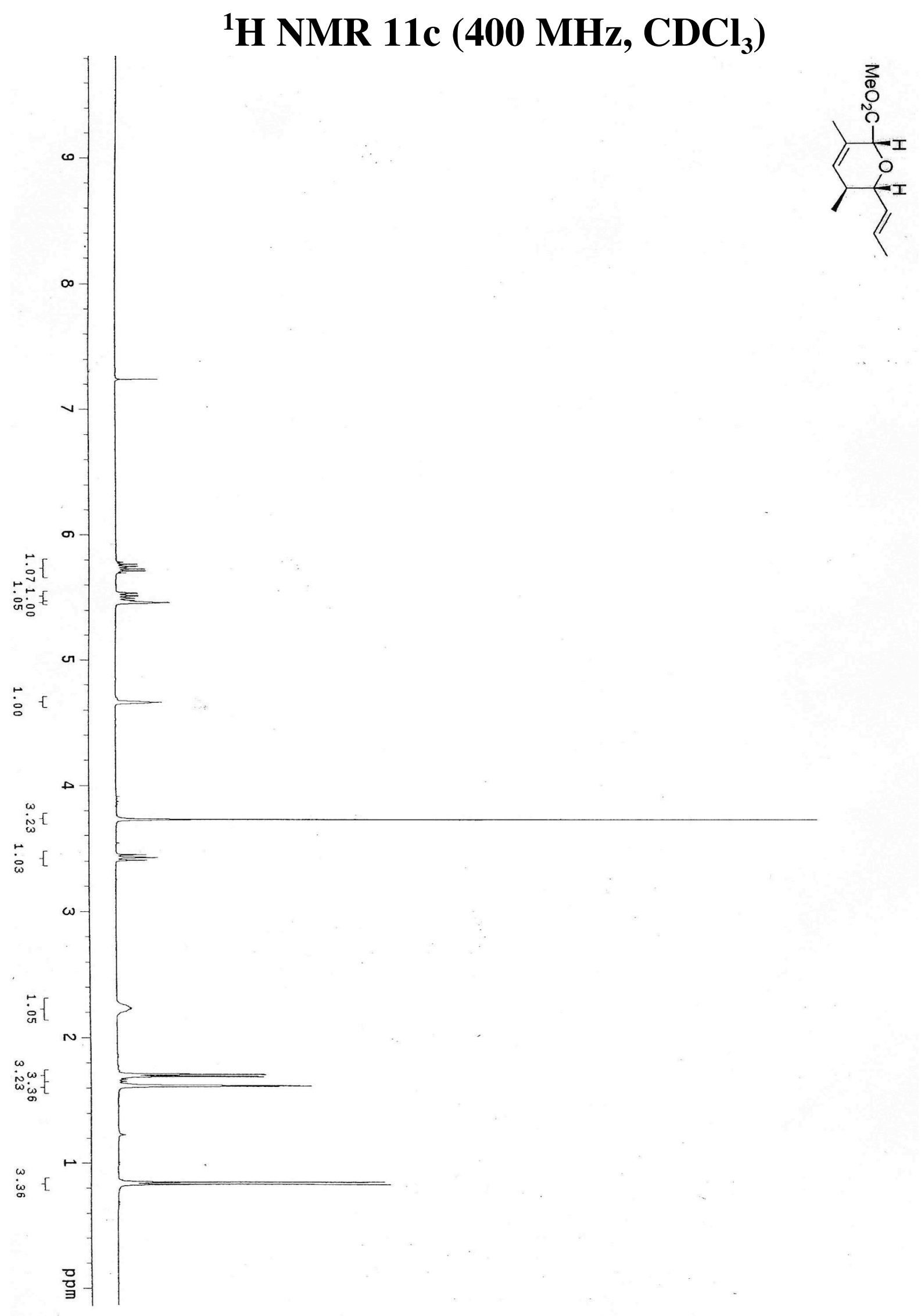

SI - 10 


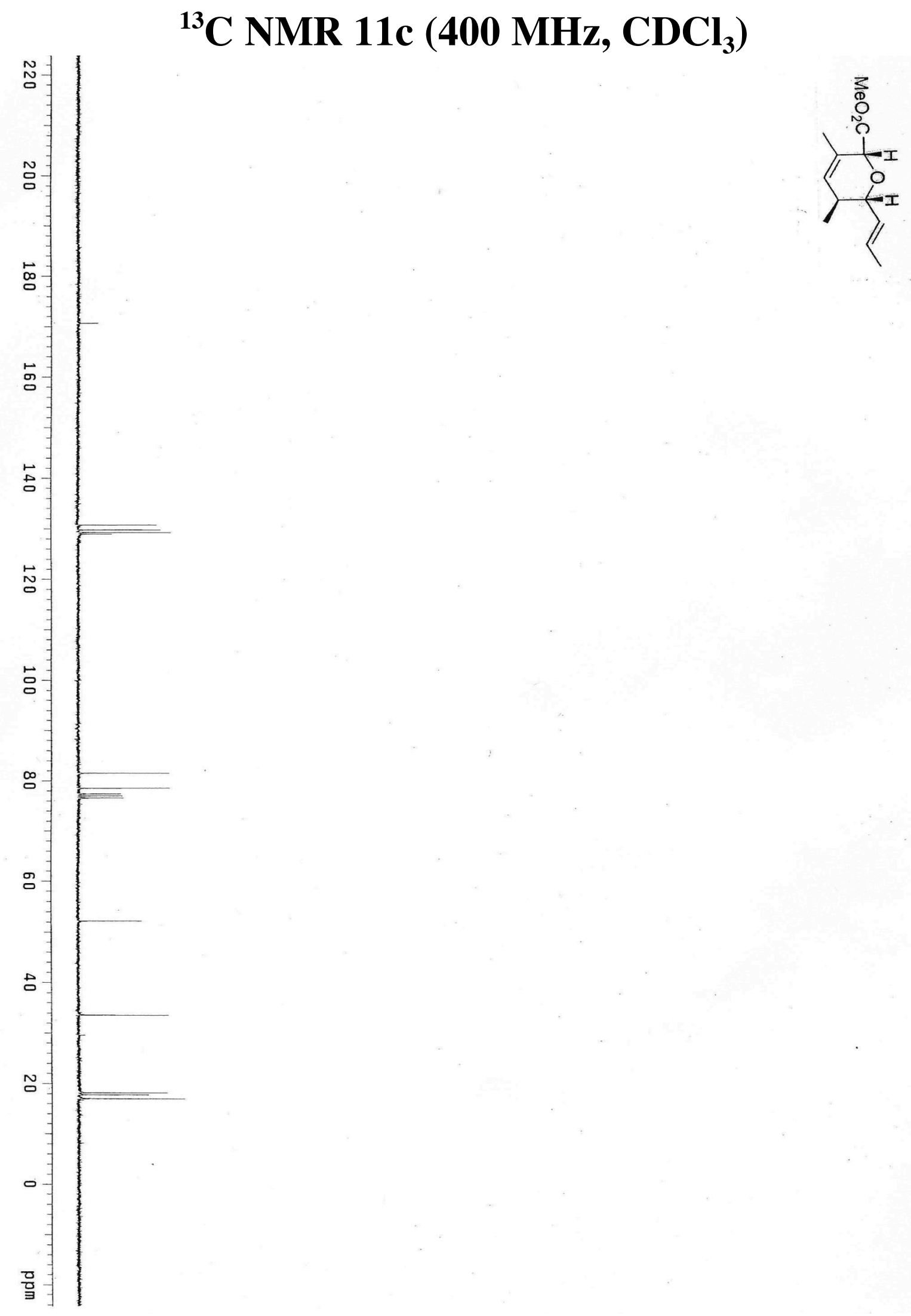




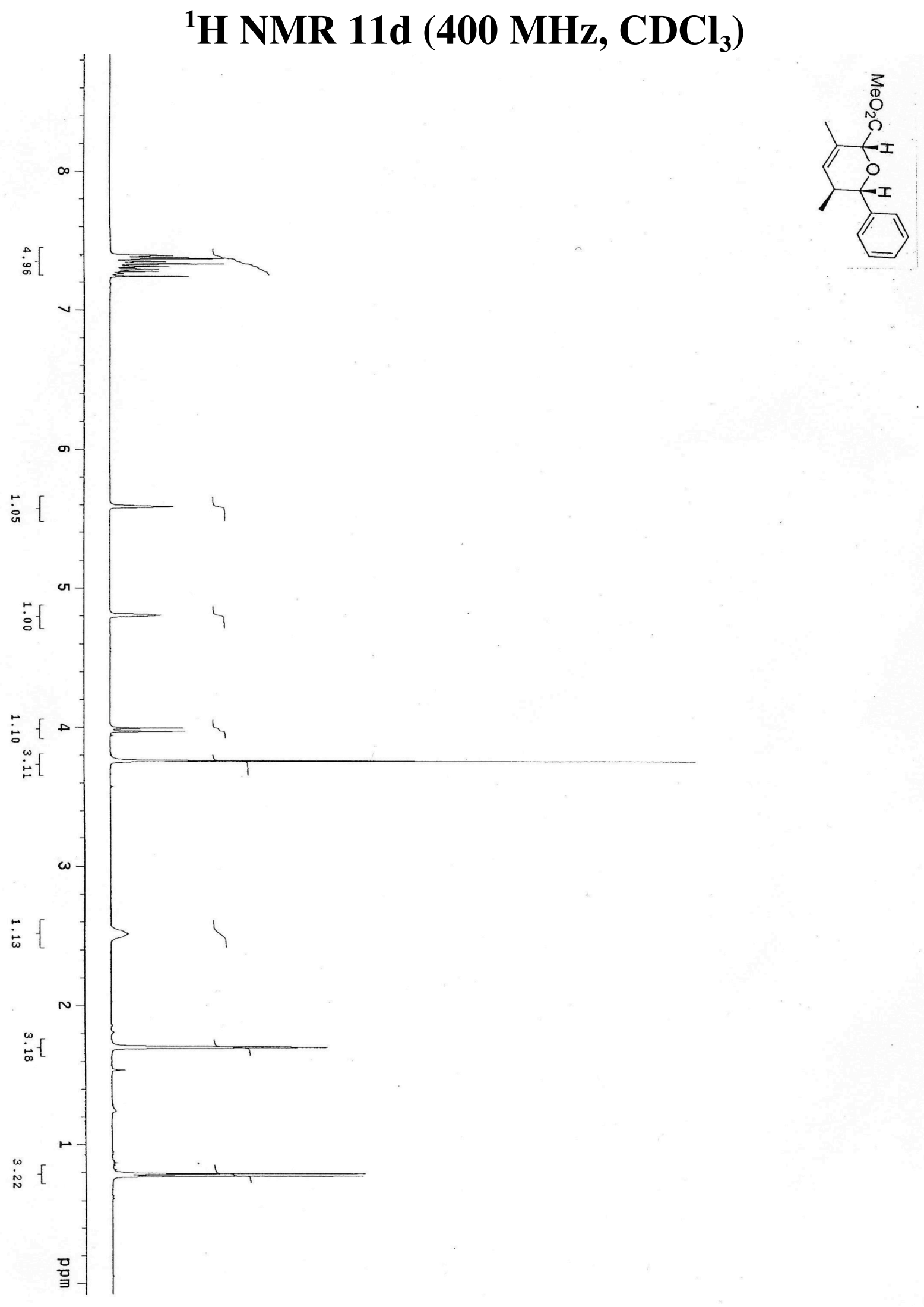




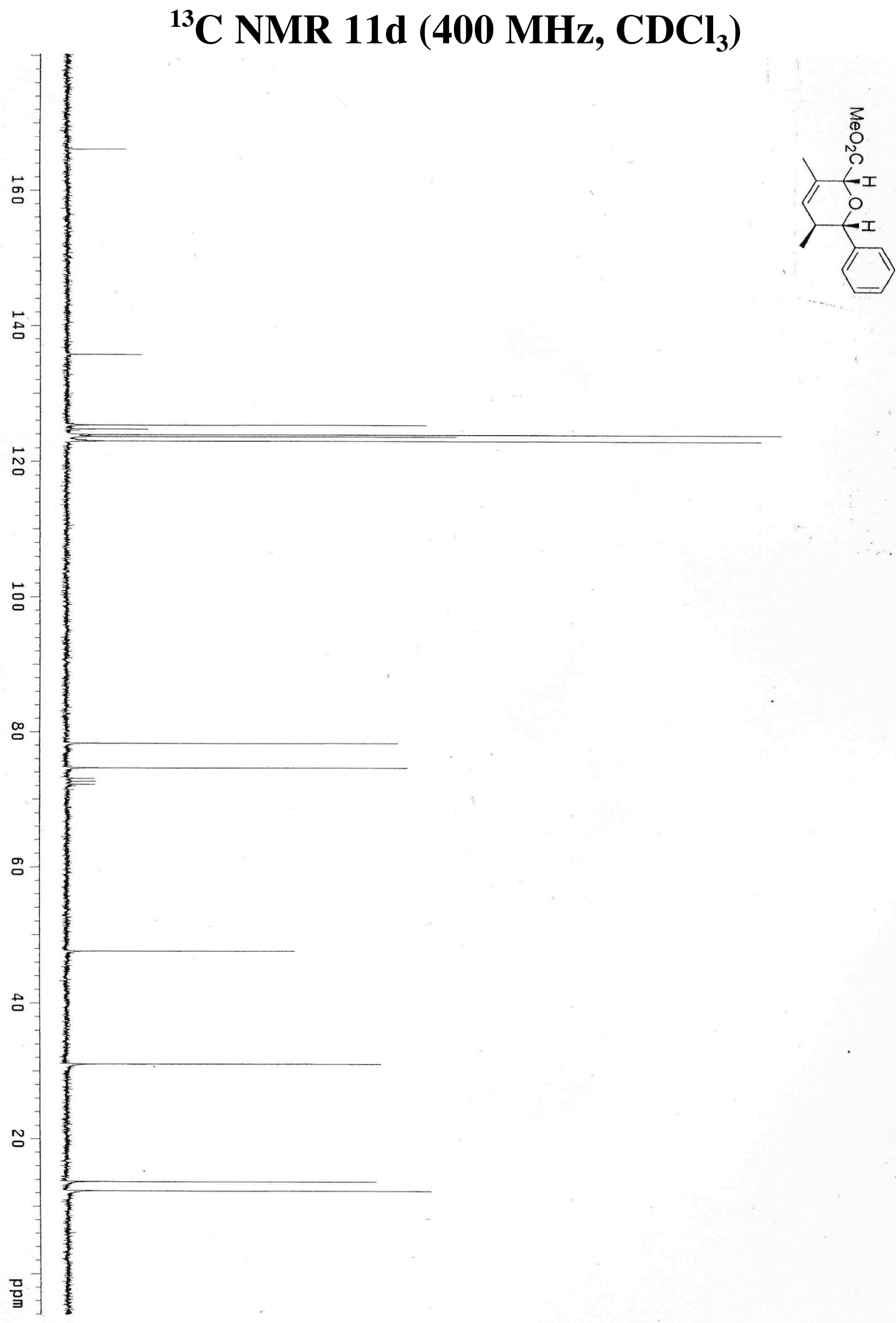

${ }^{13} \mathrm{C}$ NMR 11d (400 MHz, $\left.\mathrm{CDCl}_{3}\right)$

SI - 13 


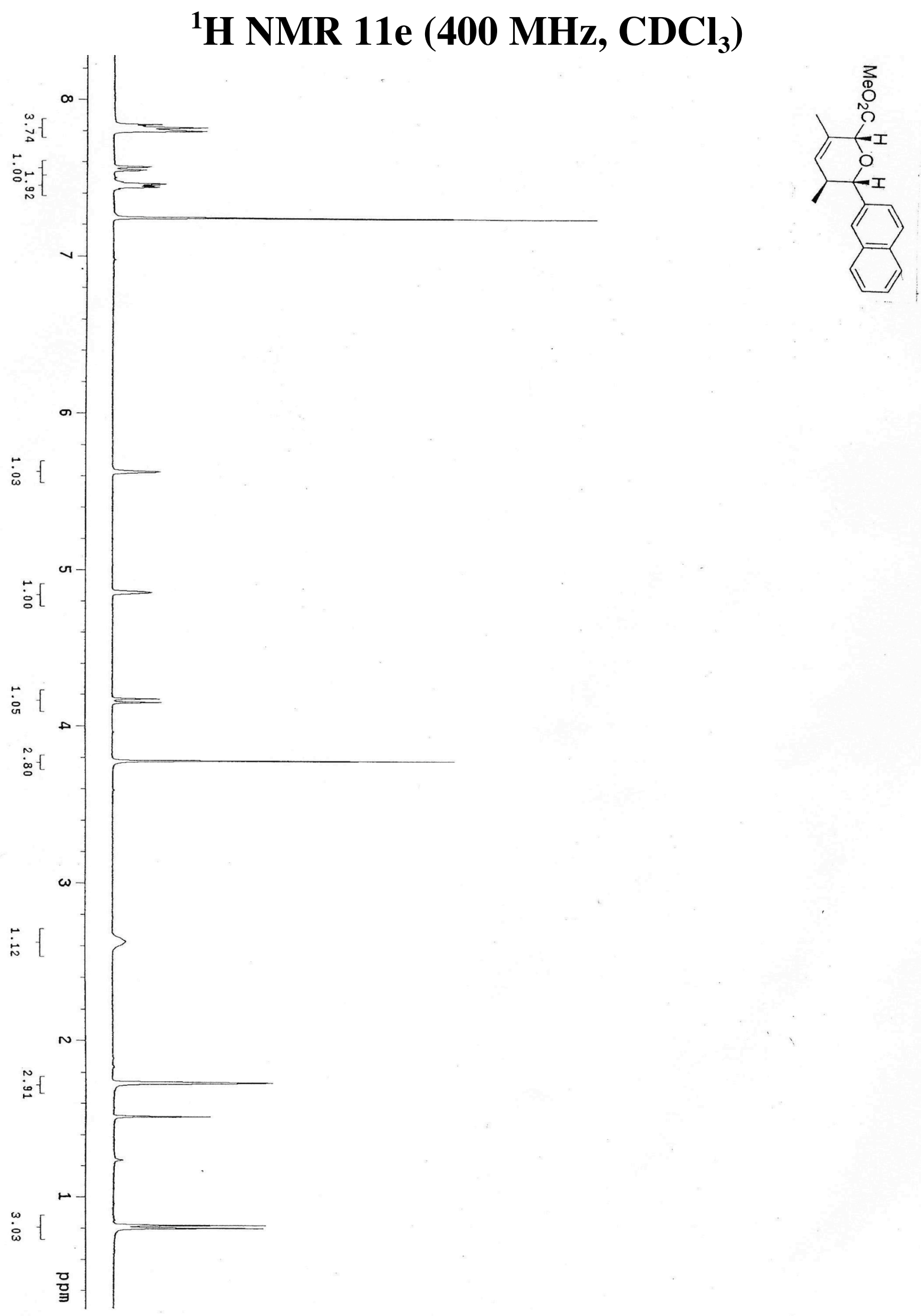

SI - 14 


\section{${ }^{13} \mathrm{C}$ NMR 11e (400 MHz, $\left.\mathrm{CDCl}_{3}\right)$}

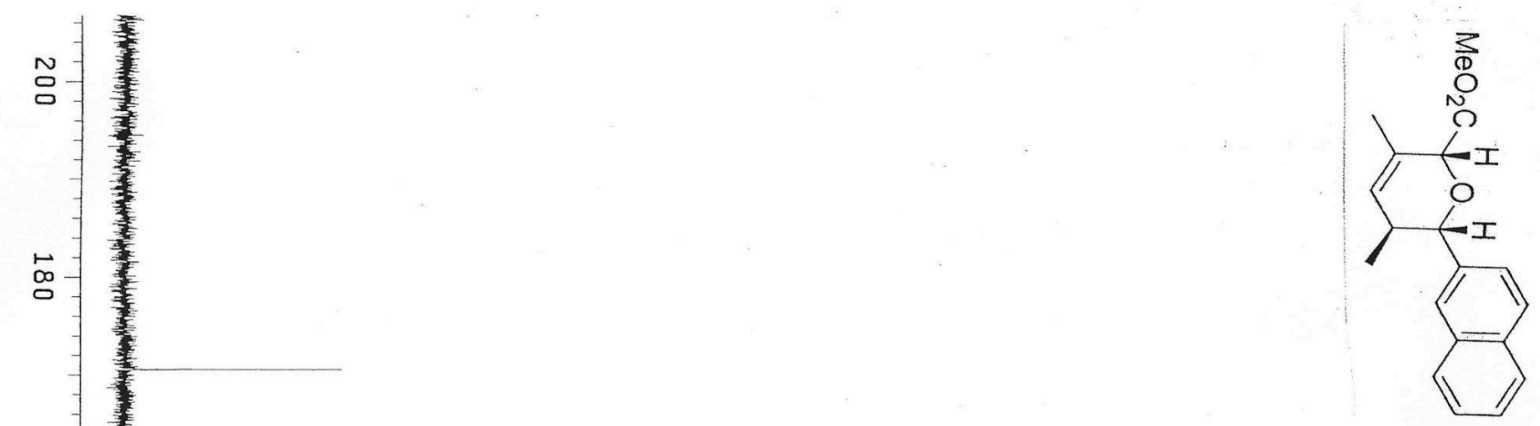

$\stackrel{\infty}{\circ}$

吕

吕-

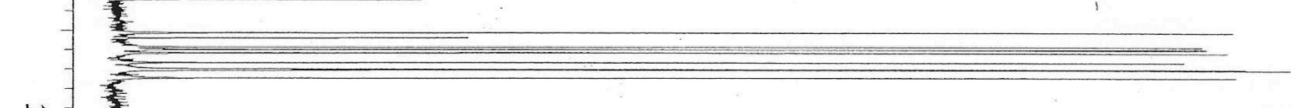

$\stackrel{\leftrightarrow}{\sim}$

몸

믐

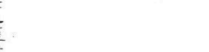

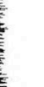
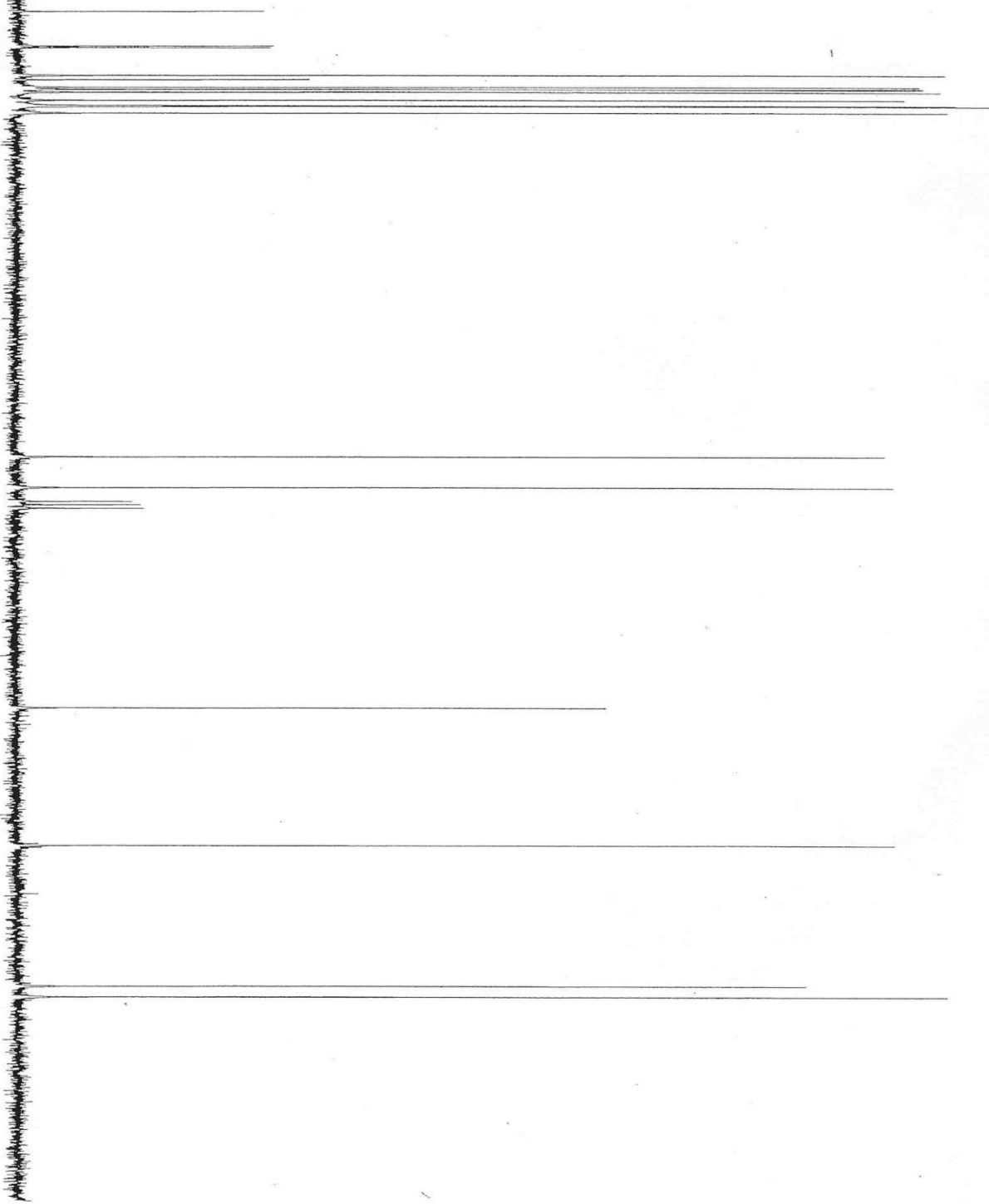

SI - 15 


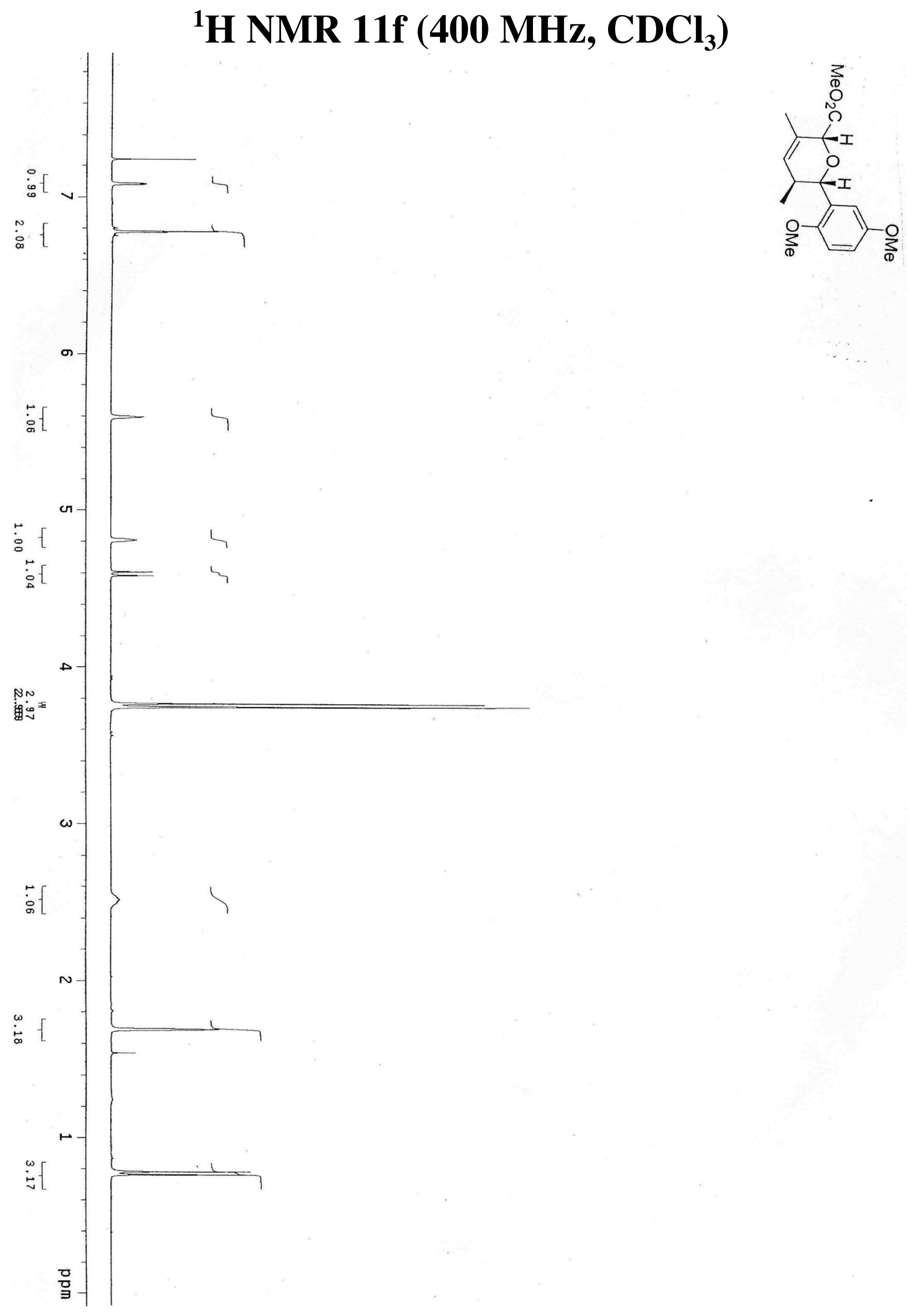

SI - 16 


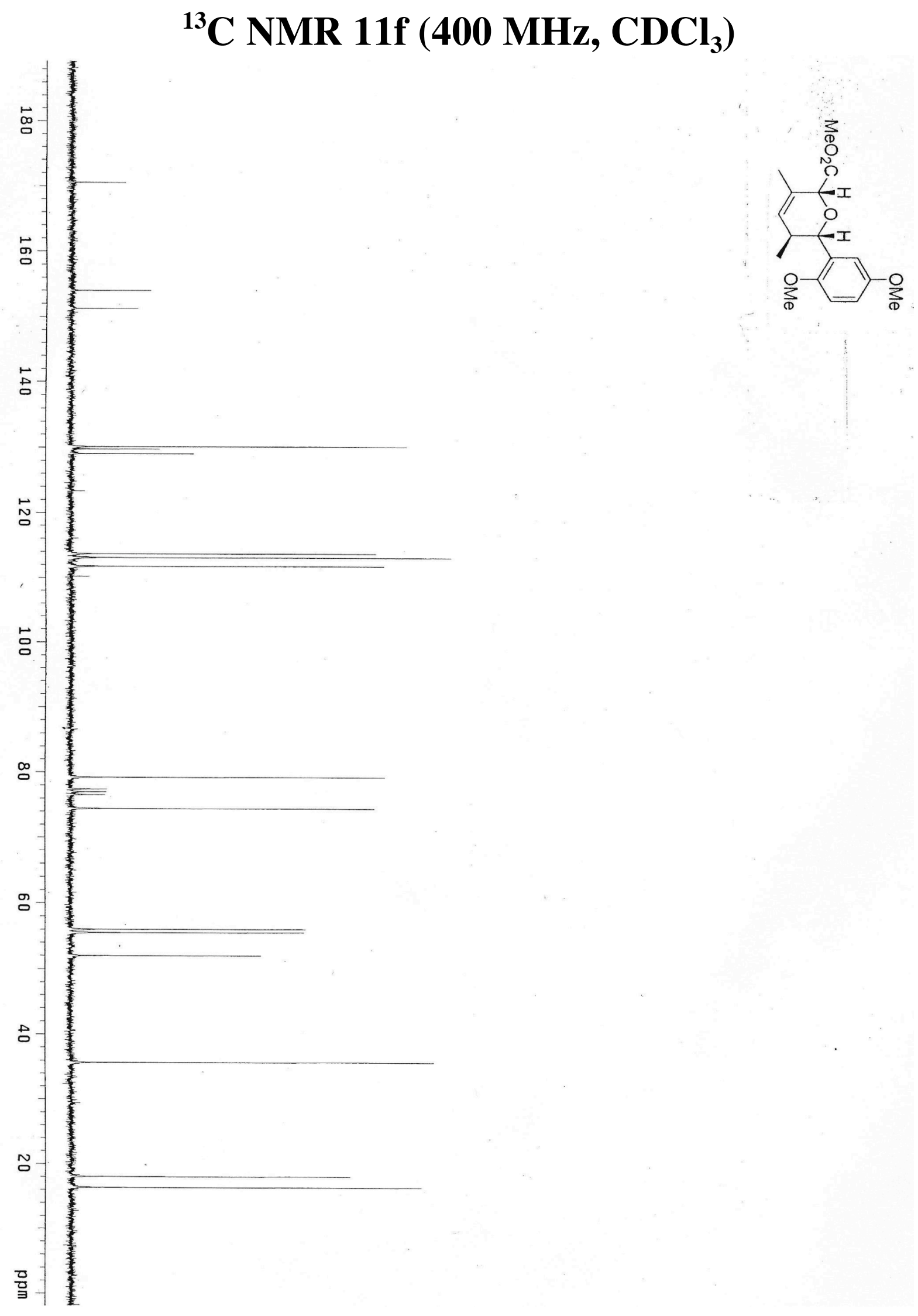

SI - 17 


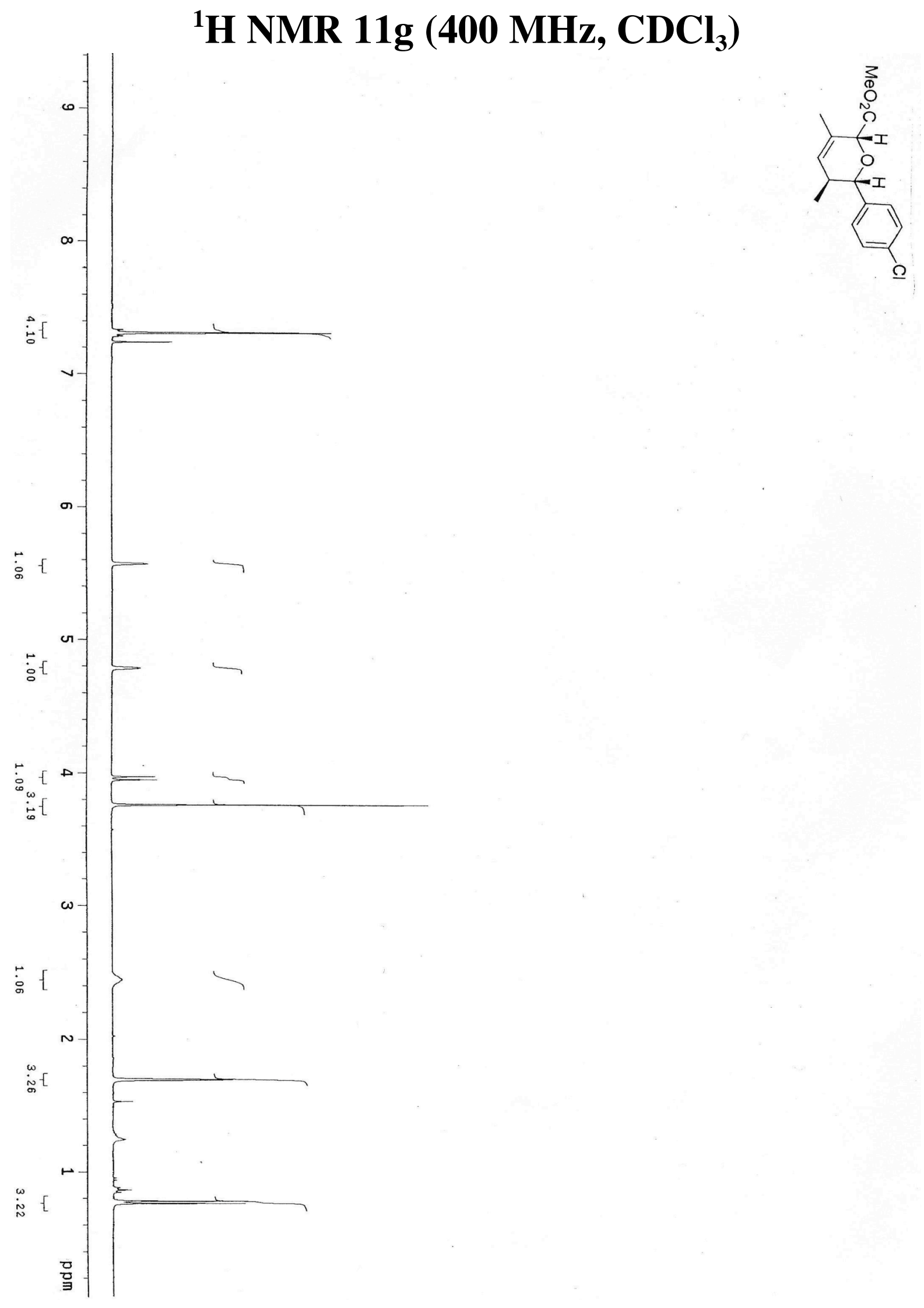

SI - 18 


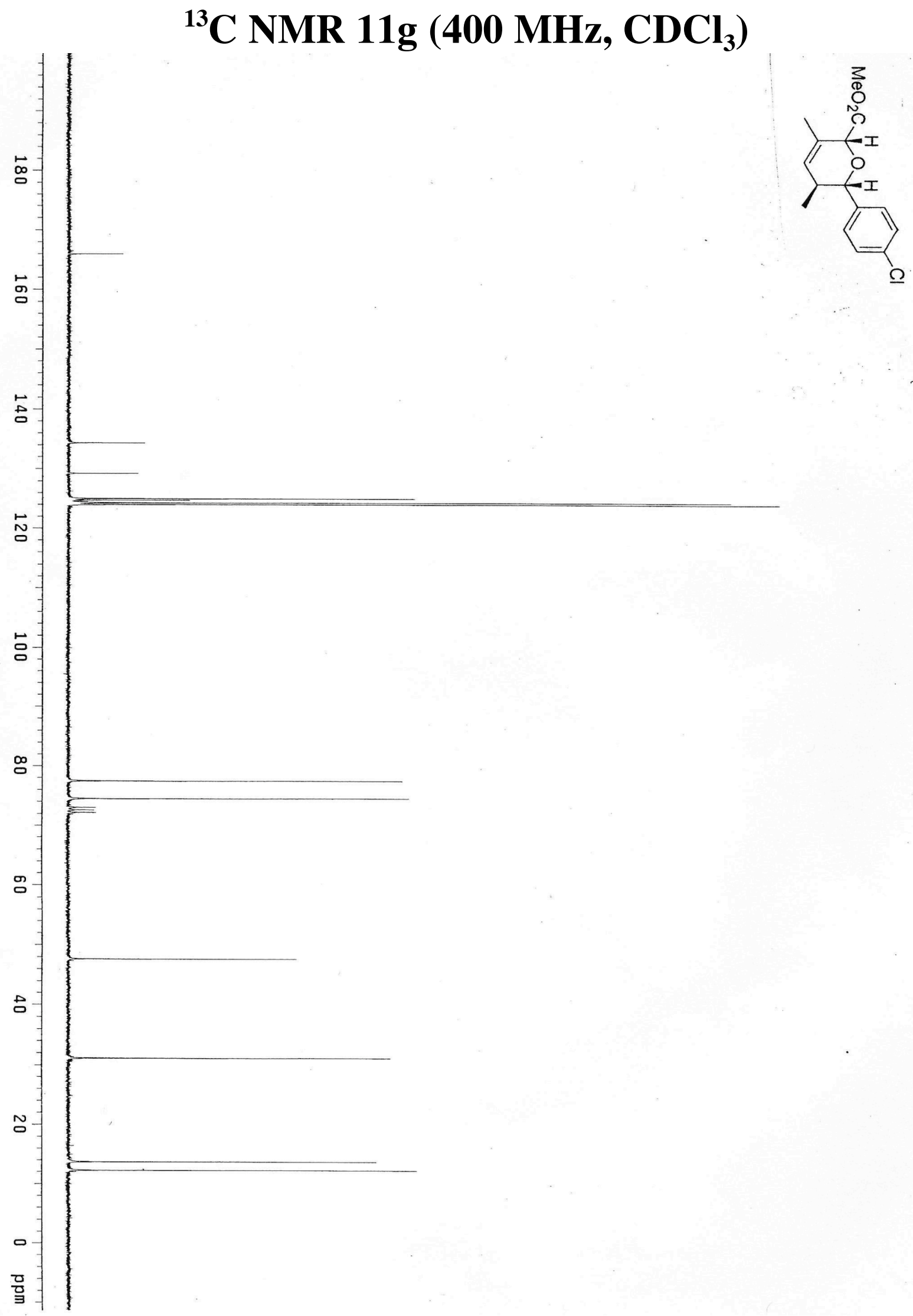

SI - 19 


\section{${ }^{1} \mathrm{H}$ NMR $11 \mathrm{~h}\left(400 \mathrm{MHz}, \mathrm{CDCl}_{3}\right)$}

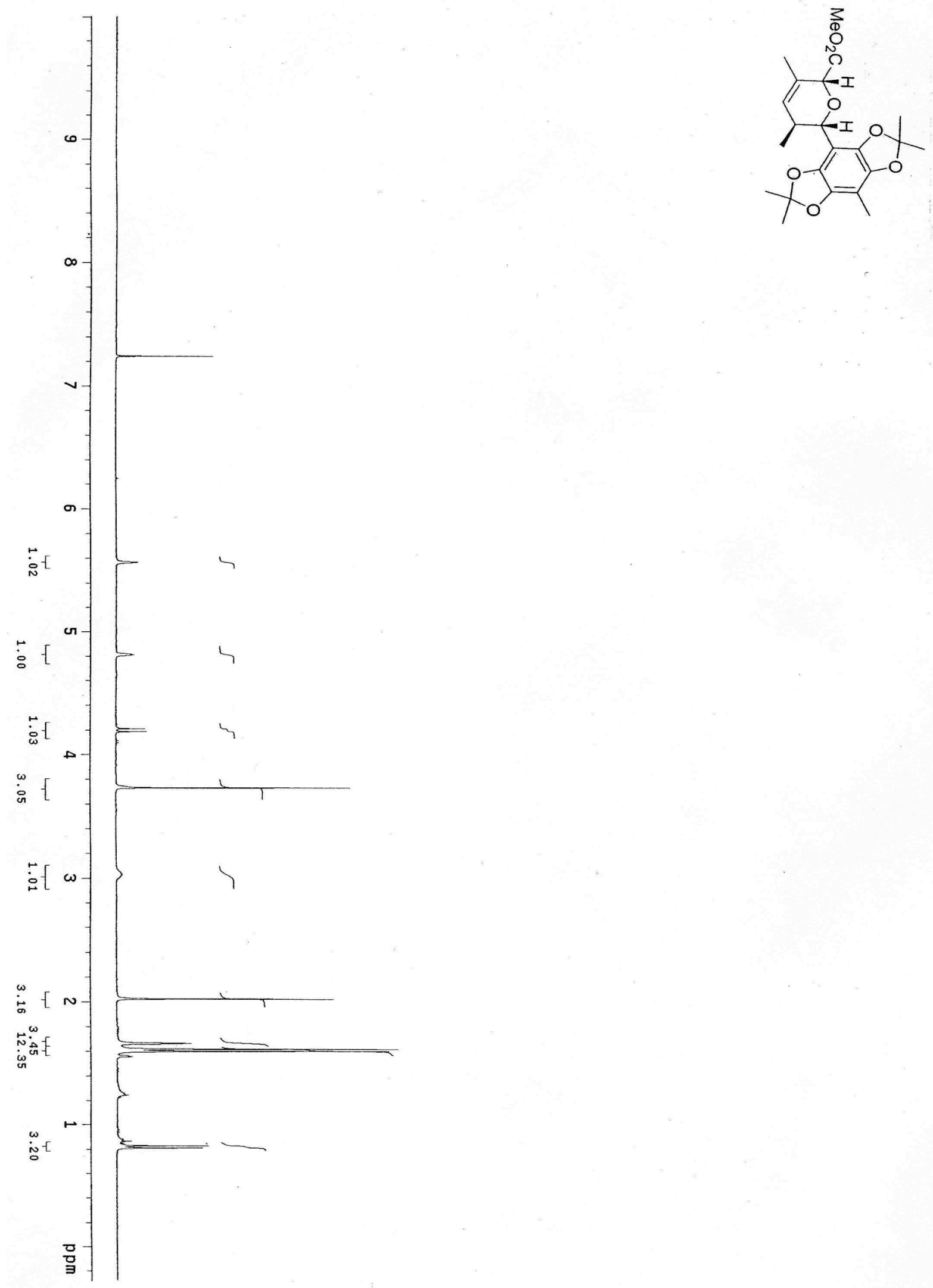




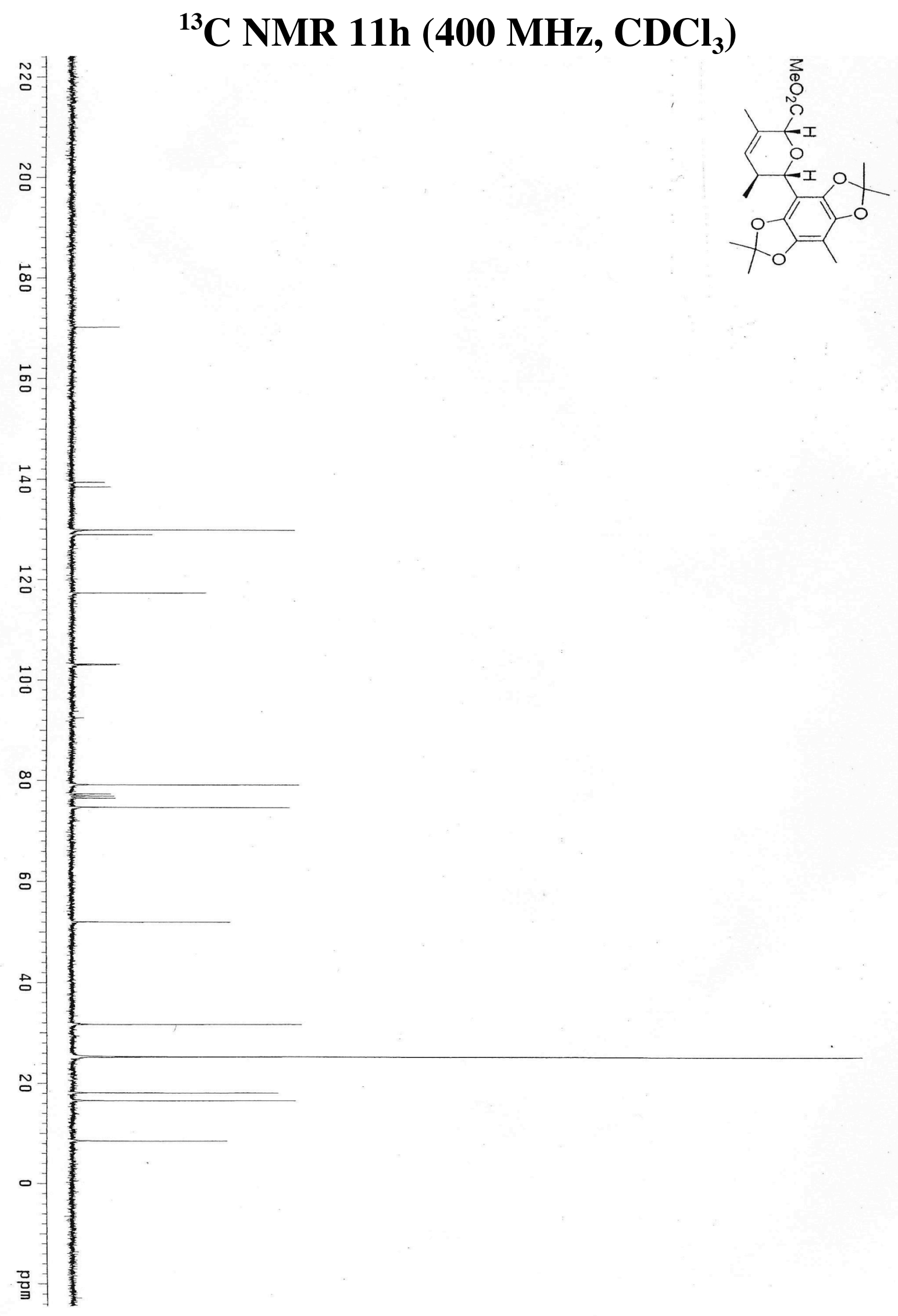

SI - 21 


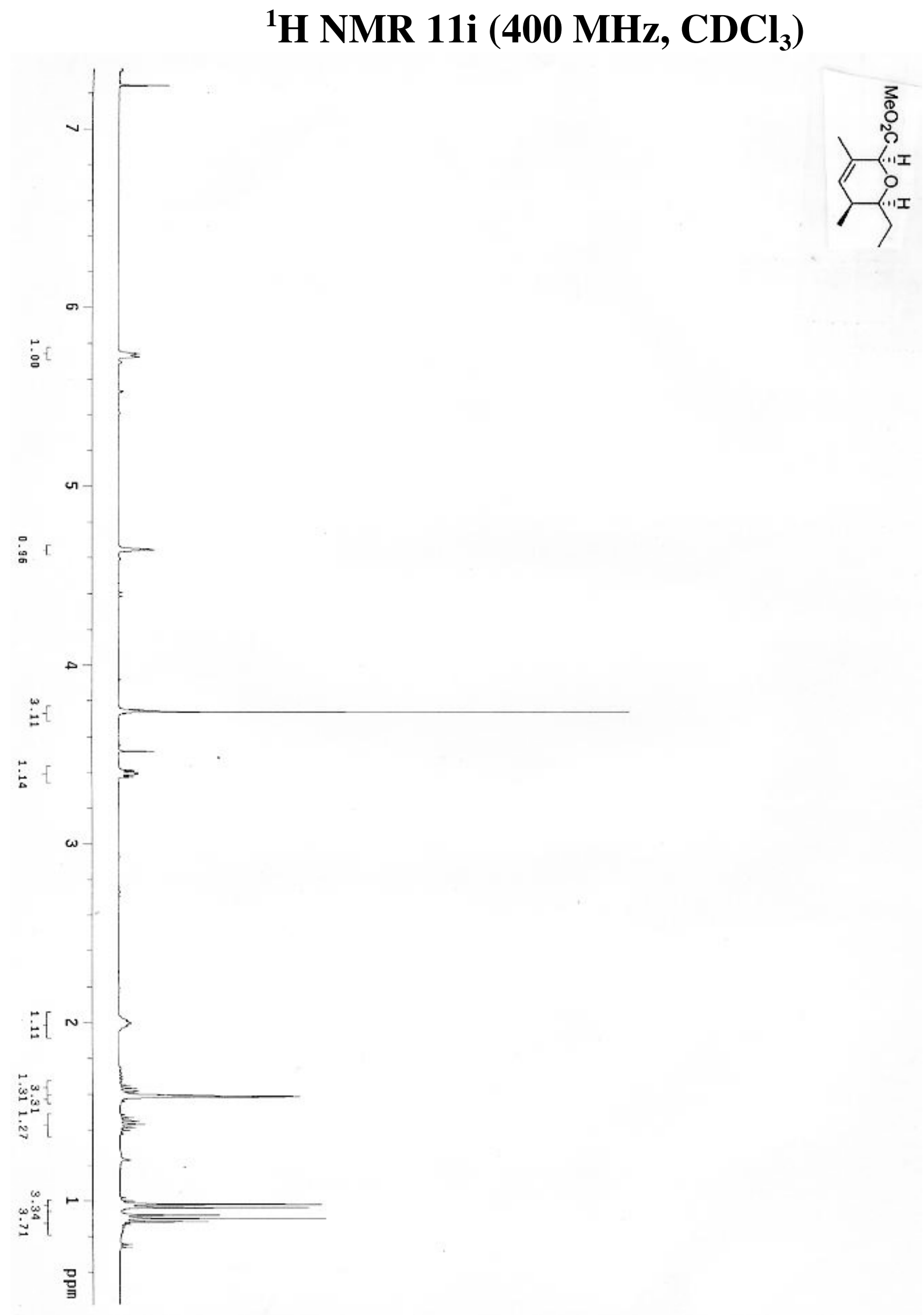


${ }^{13} \mathrm{C}$ NMR $11 \mathrm{i}\left(400 \mathrm{MHz}, \mathrm{CDCl}_{3}\right)$

SI - 23 


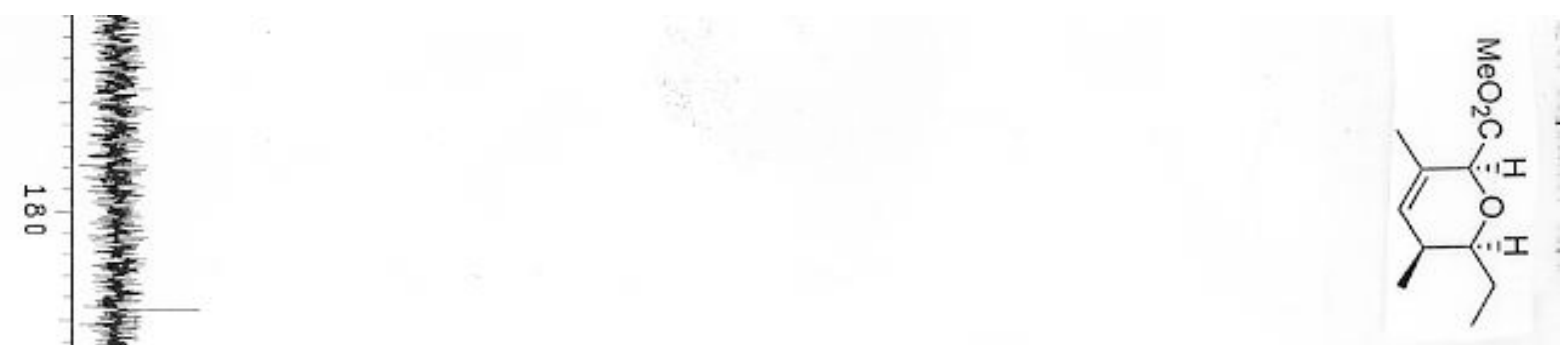

宛

$\stackrel{\leftrightarrow}{\circ}$

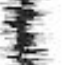

$\stackrel{5}{\circ}$

$\vdash$

응

군

$\infty$ 章

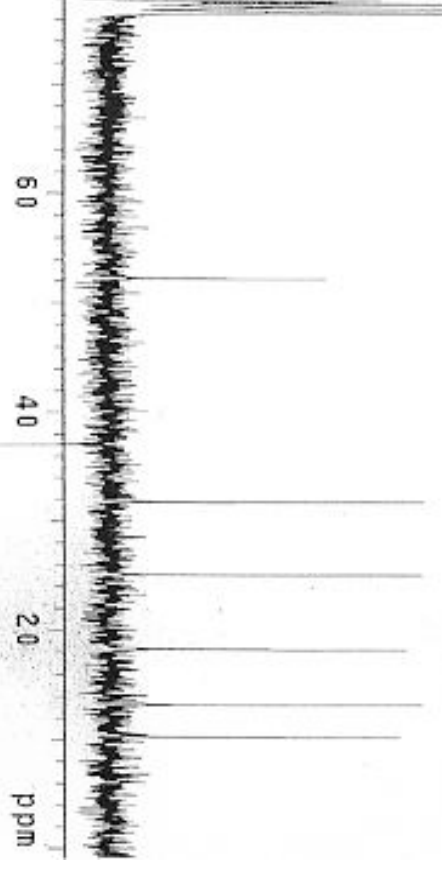




\section{${ }^{1} \mathrm{H}$ NMR 11j (400 MHz, $\mathrm{CDCl}_{3}$ )}

SI - 25 


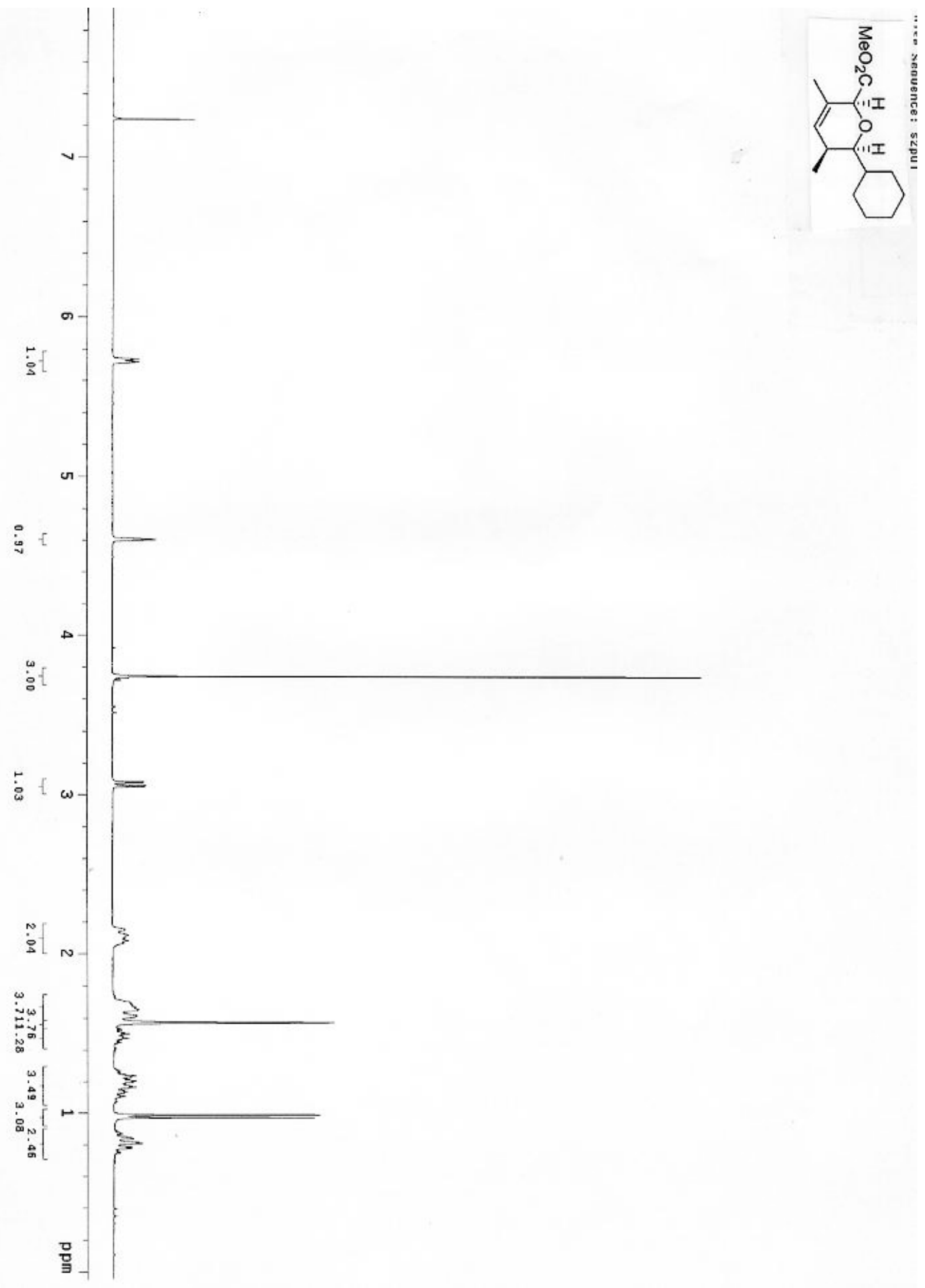




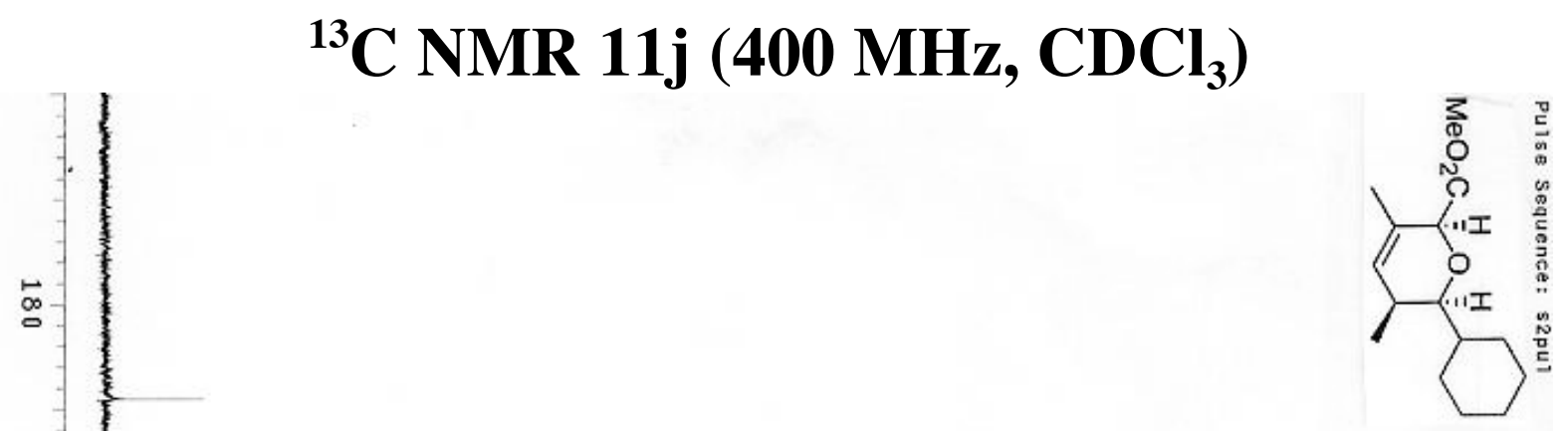

5

宫

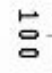

$\stackrel{\circ}{\circ}$

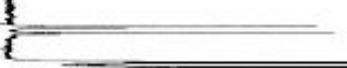

政

:

ㄱ.

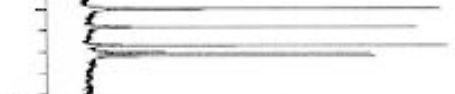

N

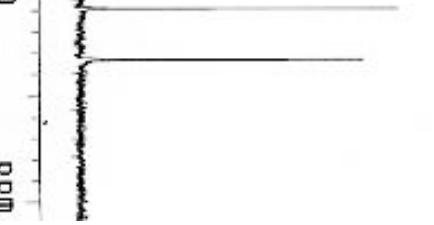

SI - 27 


\section{${ }^{1} \mathrm{H}$ NMR 11k (400 MHz, $\left.\mathrm{CDCl}_{3}\right)$}




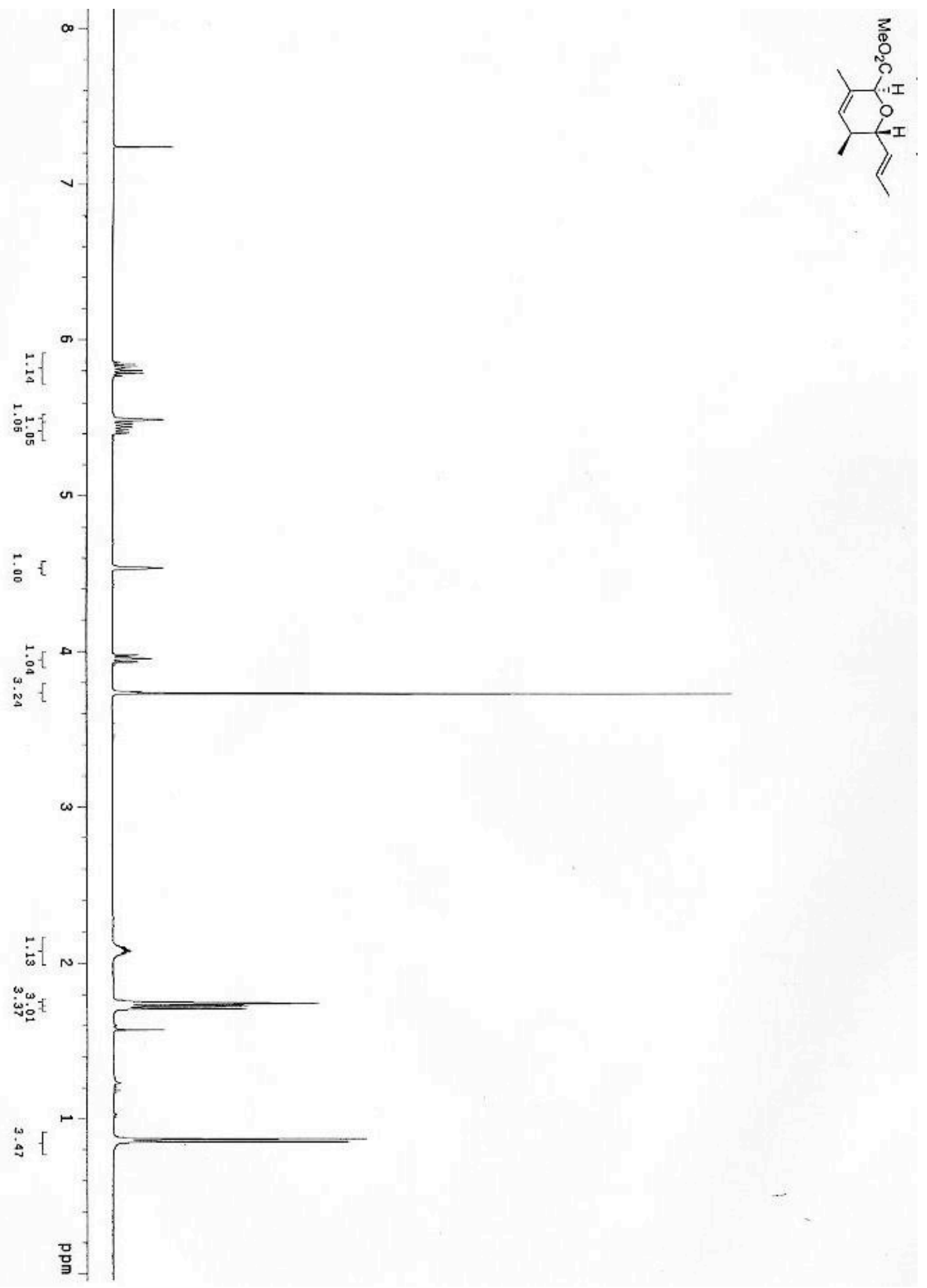



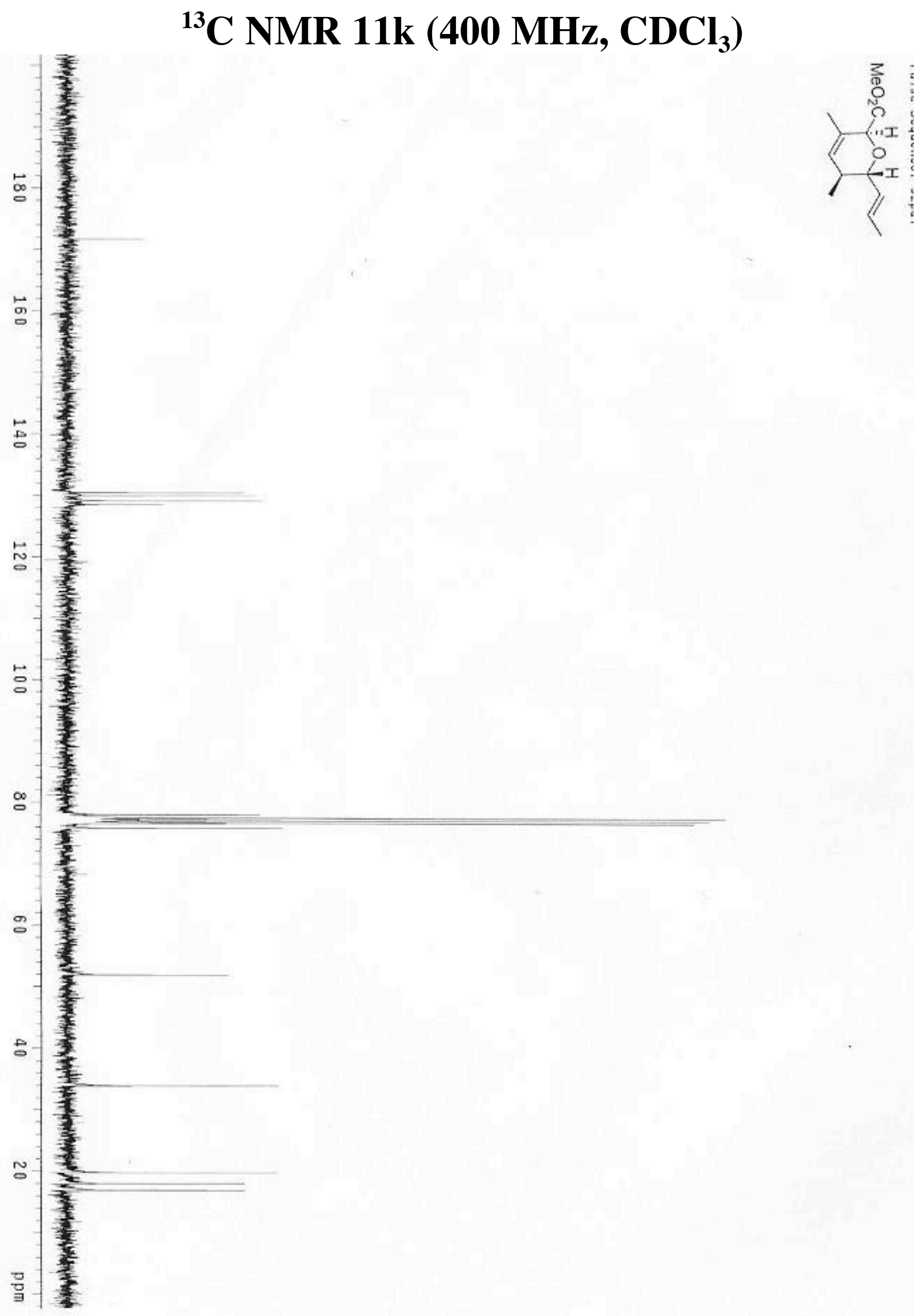

SI - 30 


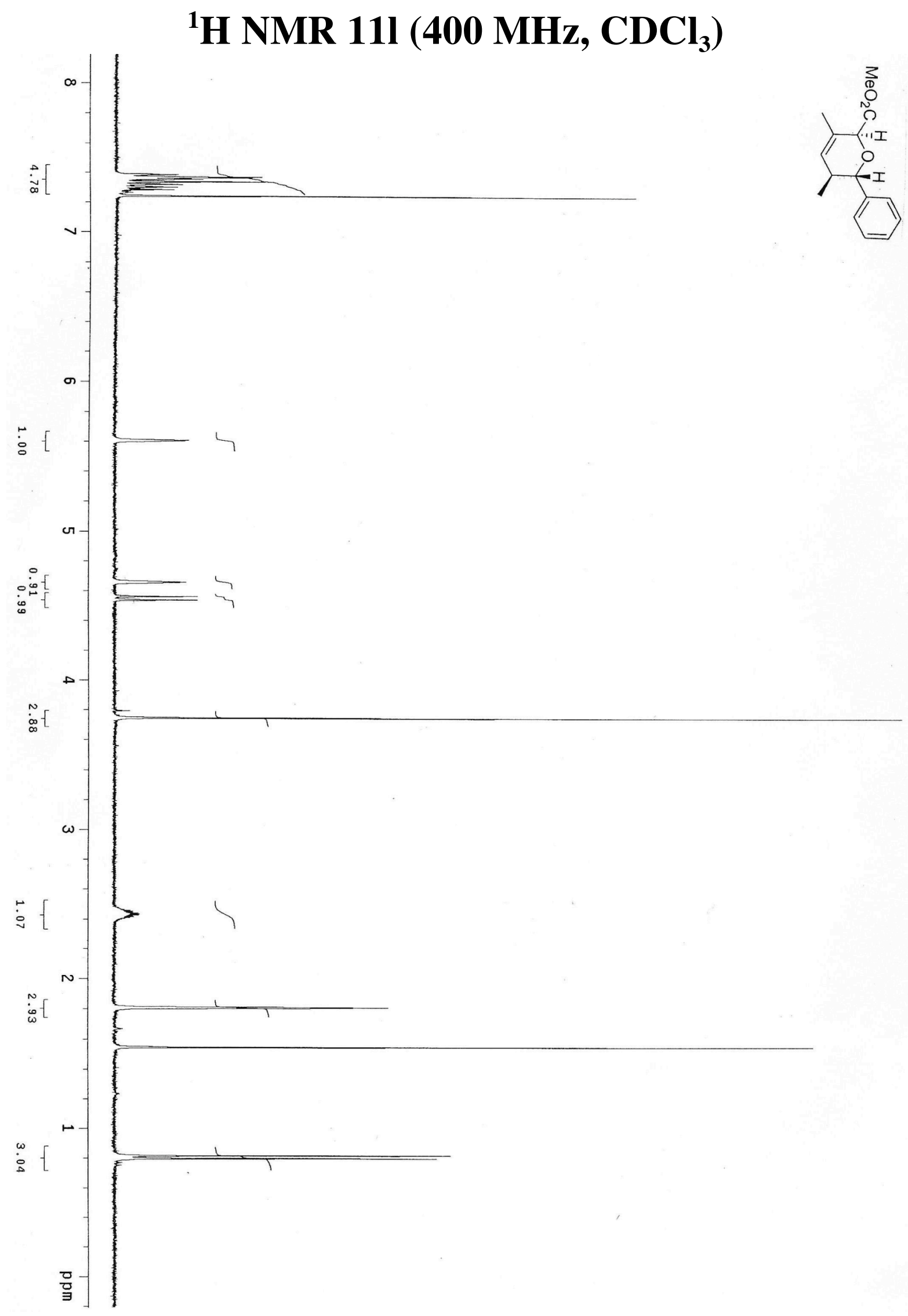

SI - 31 


\section{${ }^{13} \mathrm{C}$ NMR 111 (400 MHz, $\mathrm{CDCl}_{3}$ )}

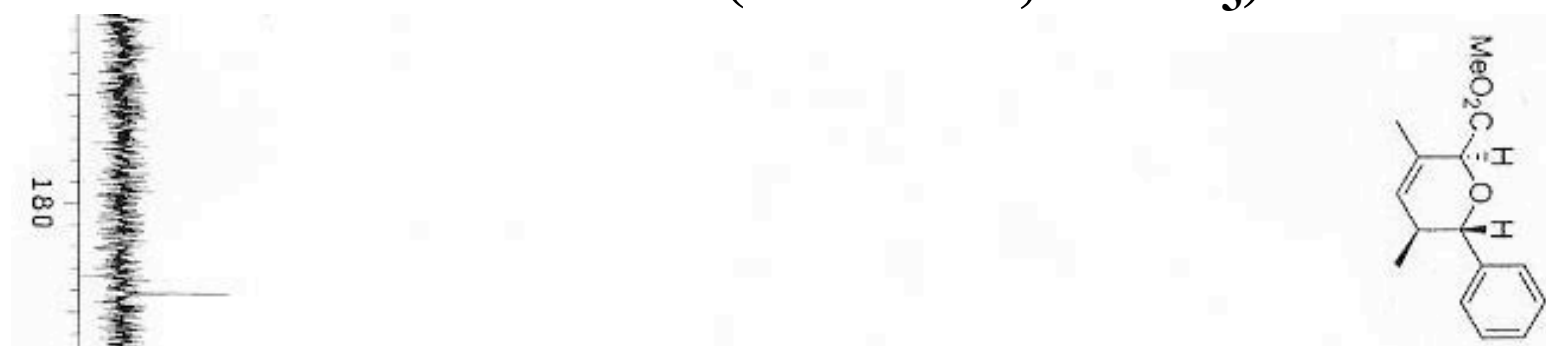

点

品

N

$\infty$

。

a

$\frac{\hat{k}}{\frac{1}{2}}$

뮴

SI - 32 


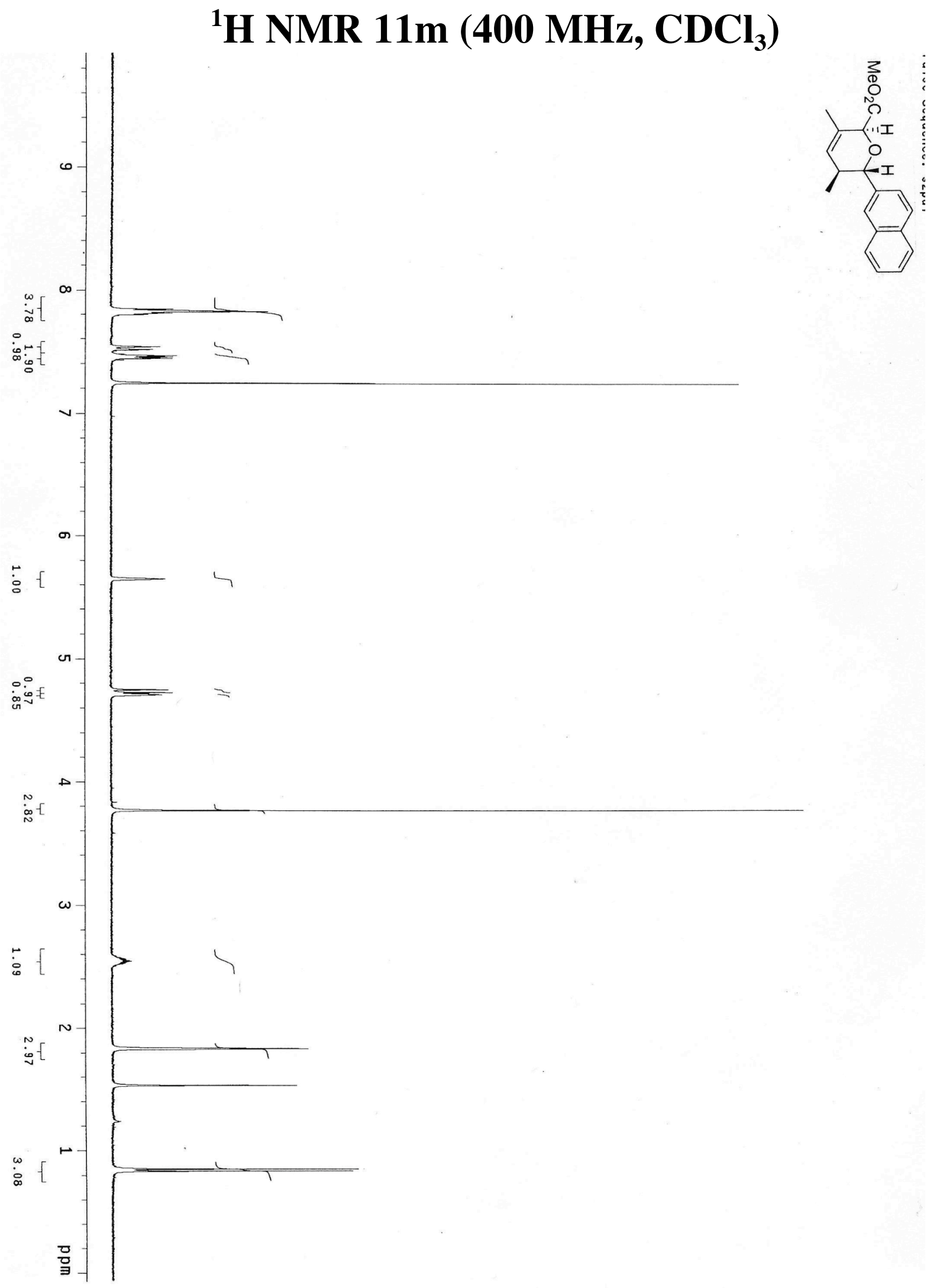

SI - 33 


\section{${ }^{13} \mathrm{C}$ NMR 11m (400 MHz, $\left.\mathrm{CDCl}_{3}\right)$}

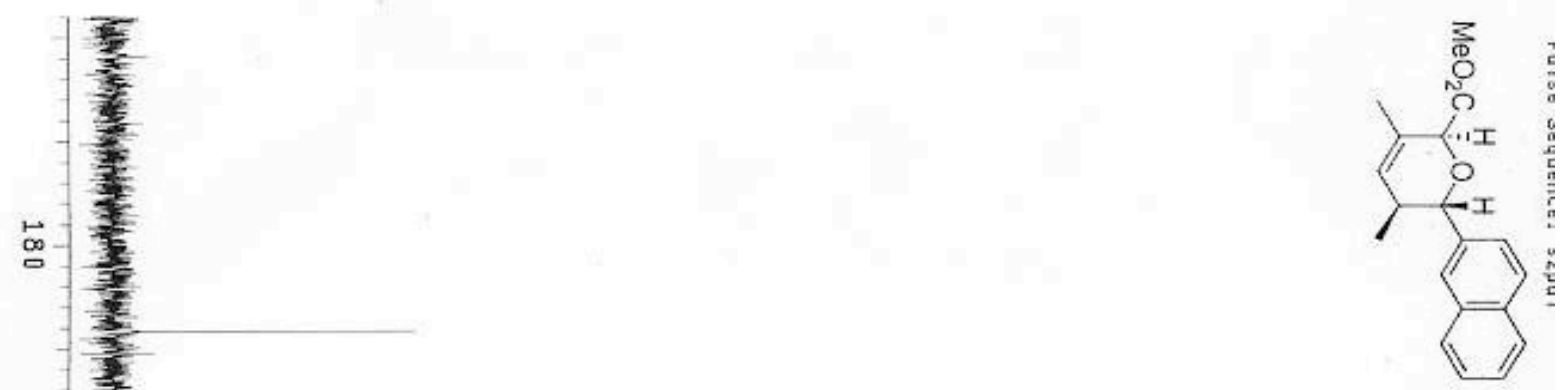

晏

吕

-

$\underset{0}{\stackrel{5}{0}}$

$0-$

娄

응

年

$\infty$ 辛

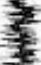

-

$-\frac{1}{3}$ 


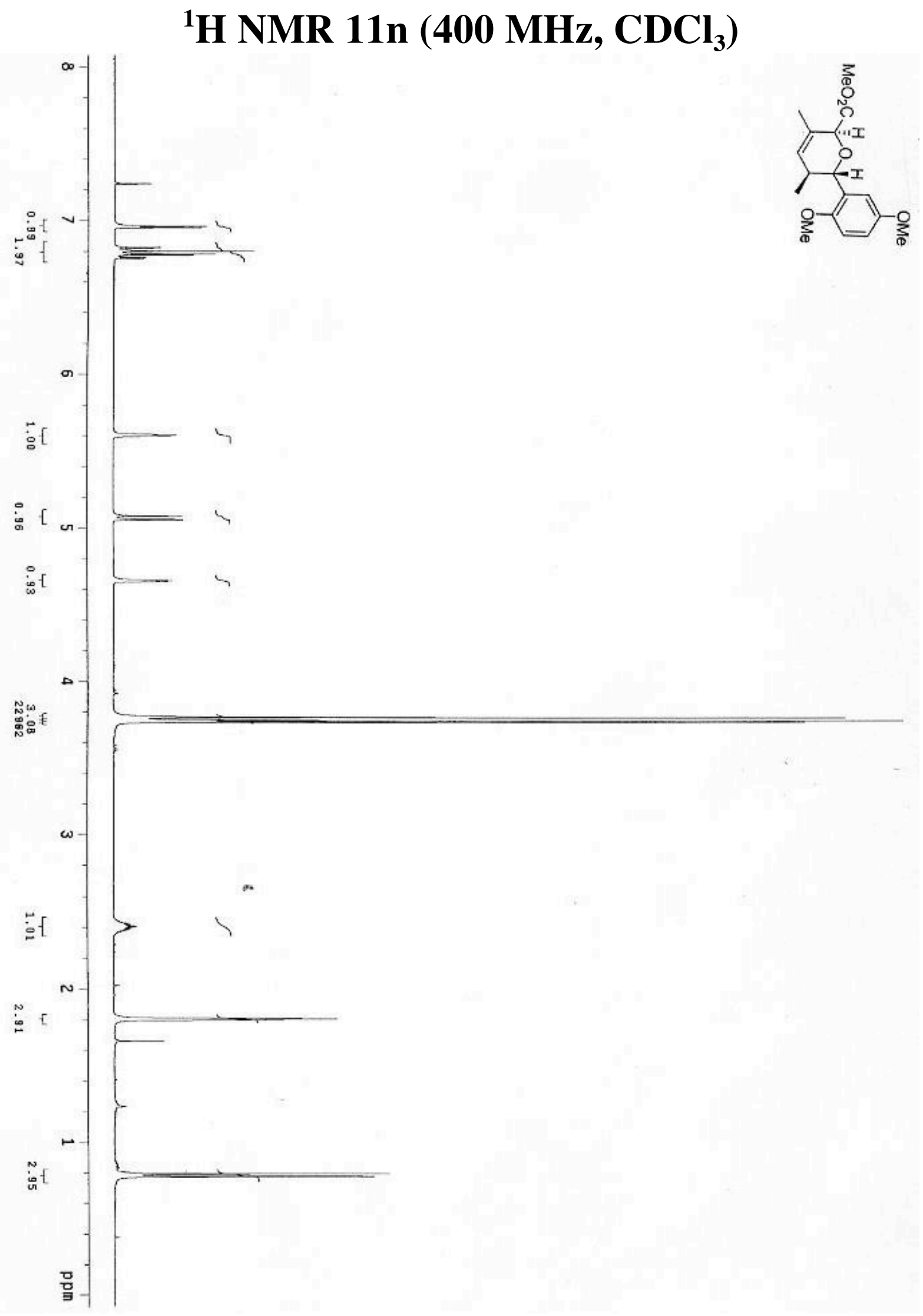




\section{${ }^{13} \mathrm{C}$ NMR 11n $\left(400 \mathrm{MHz}, \mathrm{CDCl}_{3}\right)$}

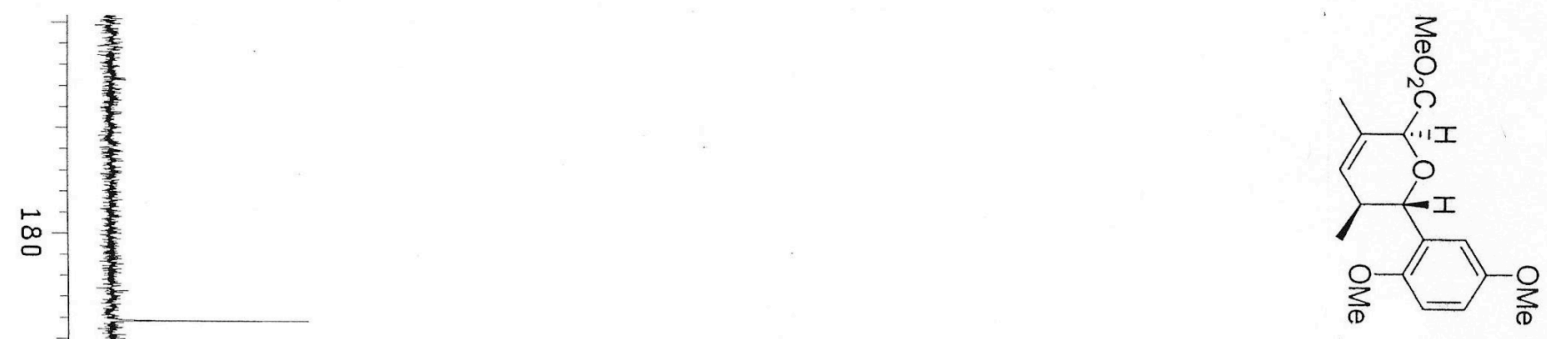

$\stackrel{\infty}{\circ}$

등-

N

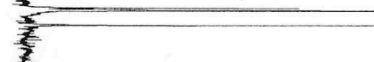

ㅁ-ㄱ-

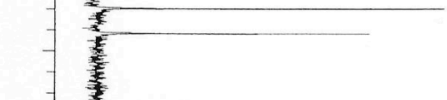

$\stackrel{b}{\stackrel{b}{a}}$

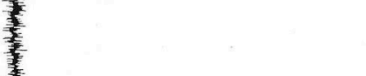

$\frac{1}{4}$

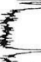

a

a-

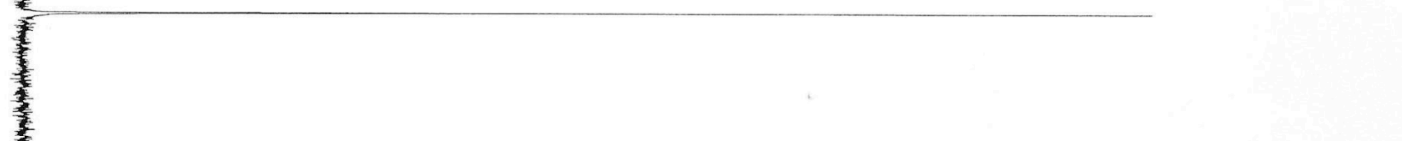

-

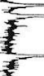

듭.

SI - 36 


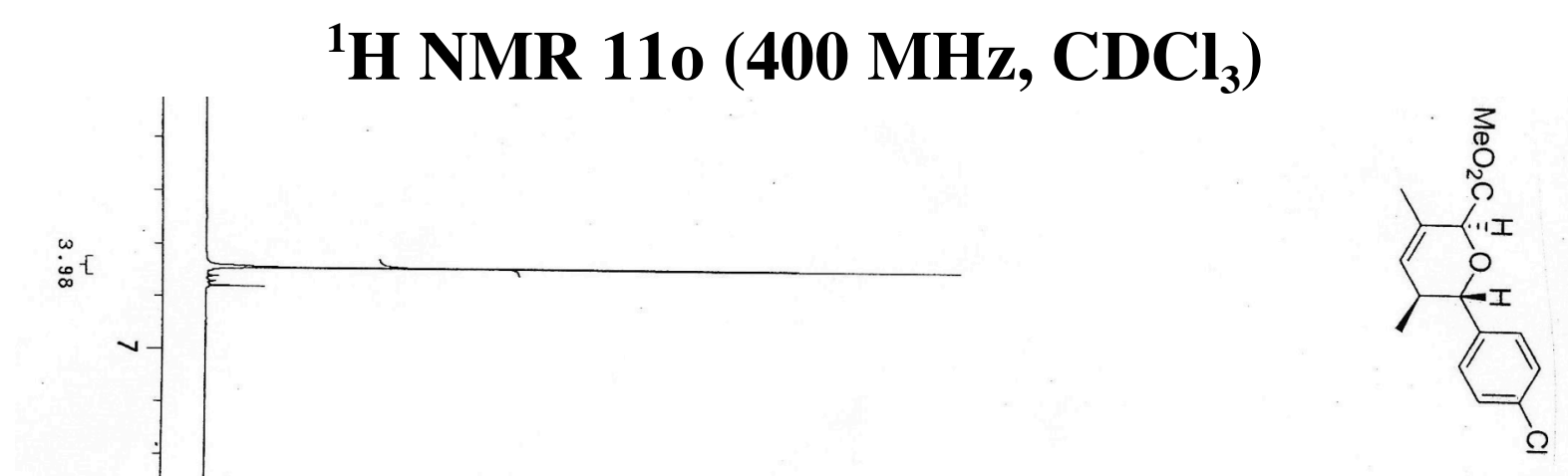




\section{${ }^{13} \mathrm{C}$ NMR $110\left(400 \mathrm{MHz}, \mathrm{CDCl}_{3}\right)$}
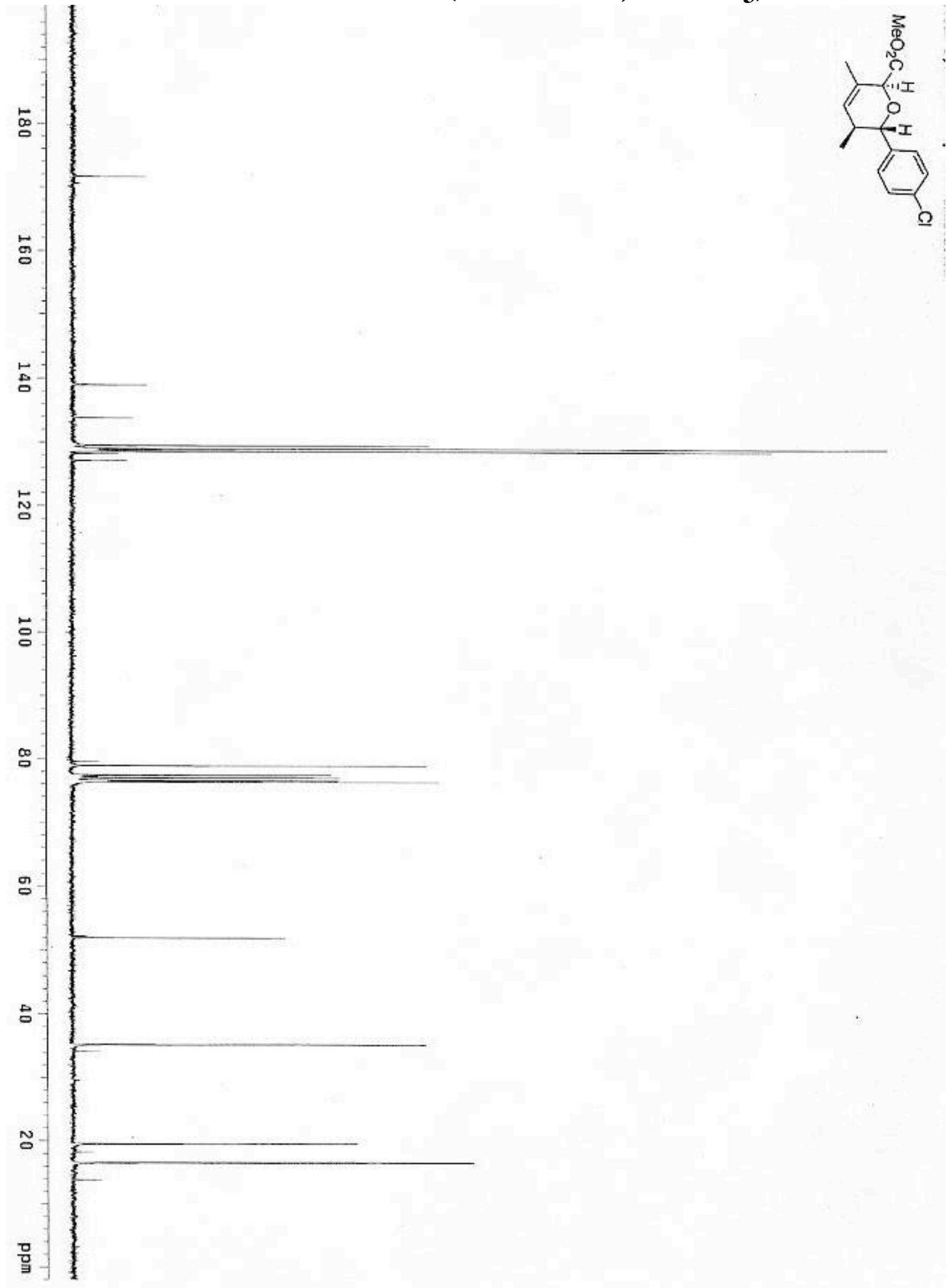

SI - 38 


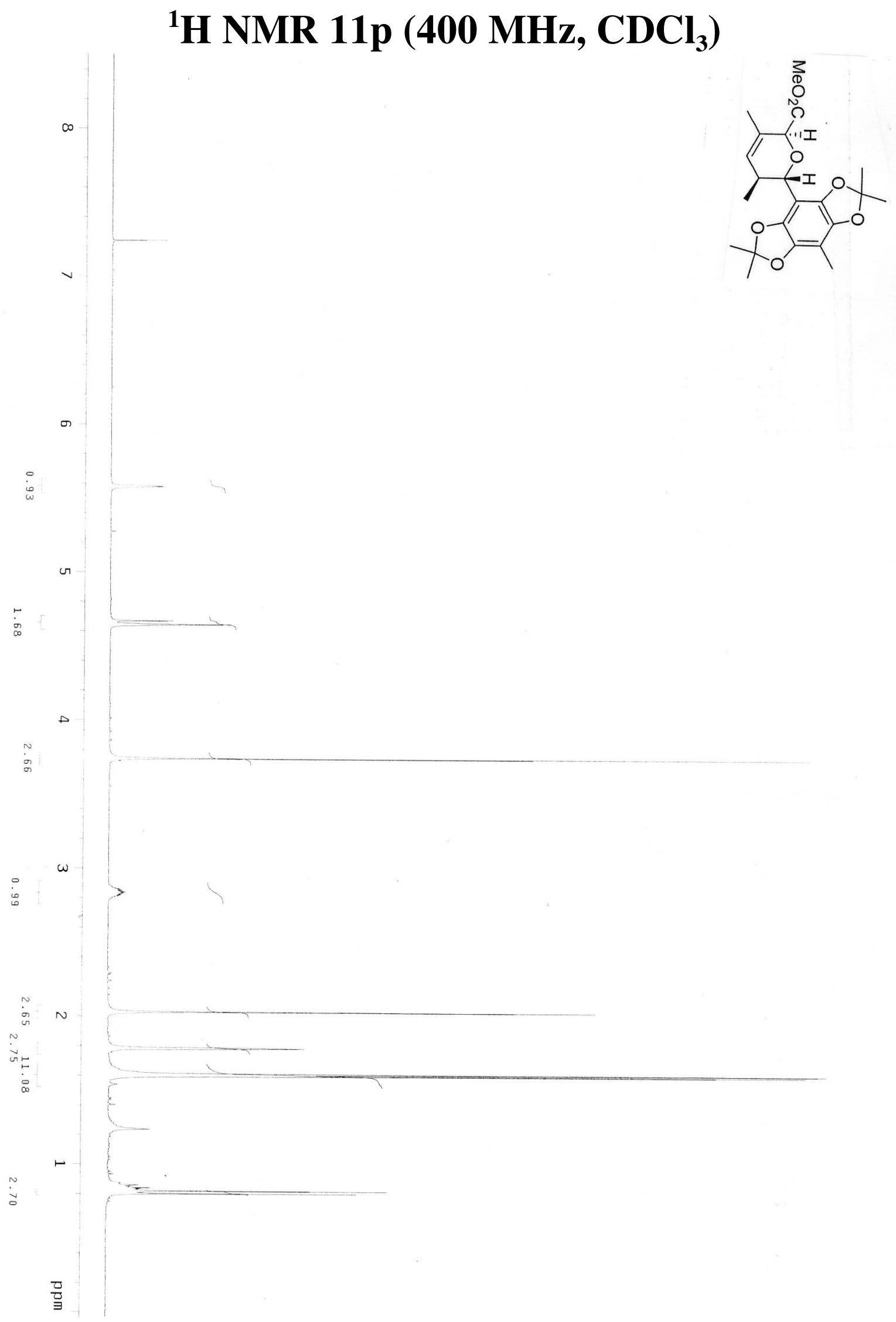




\section{${ }^{13} \mathrm{C}$ NMR 11p (400 MHz, $\left.\mathrm{CDCl}_{3}\right)$}

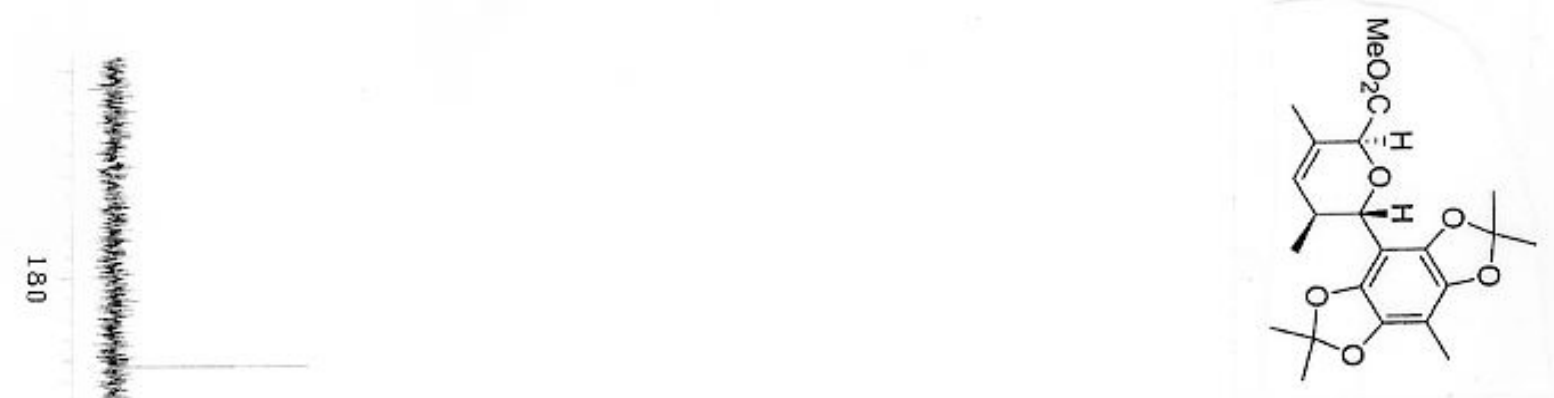

$\stackrel{\infty}{\circ}$

E

$\stackrel{N}{0}$

$\leftleftarrows$

홍

章

3

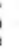

妾

娄

9 妾

B 旁

$\frac{k}{5}$

$\simeq$

呈售 


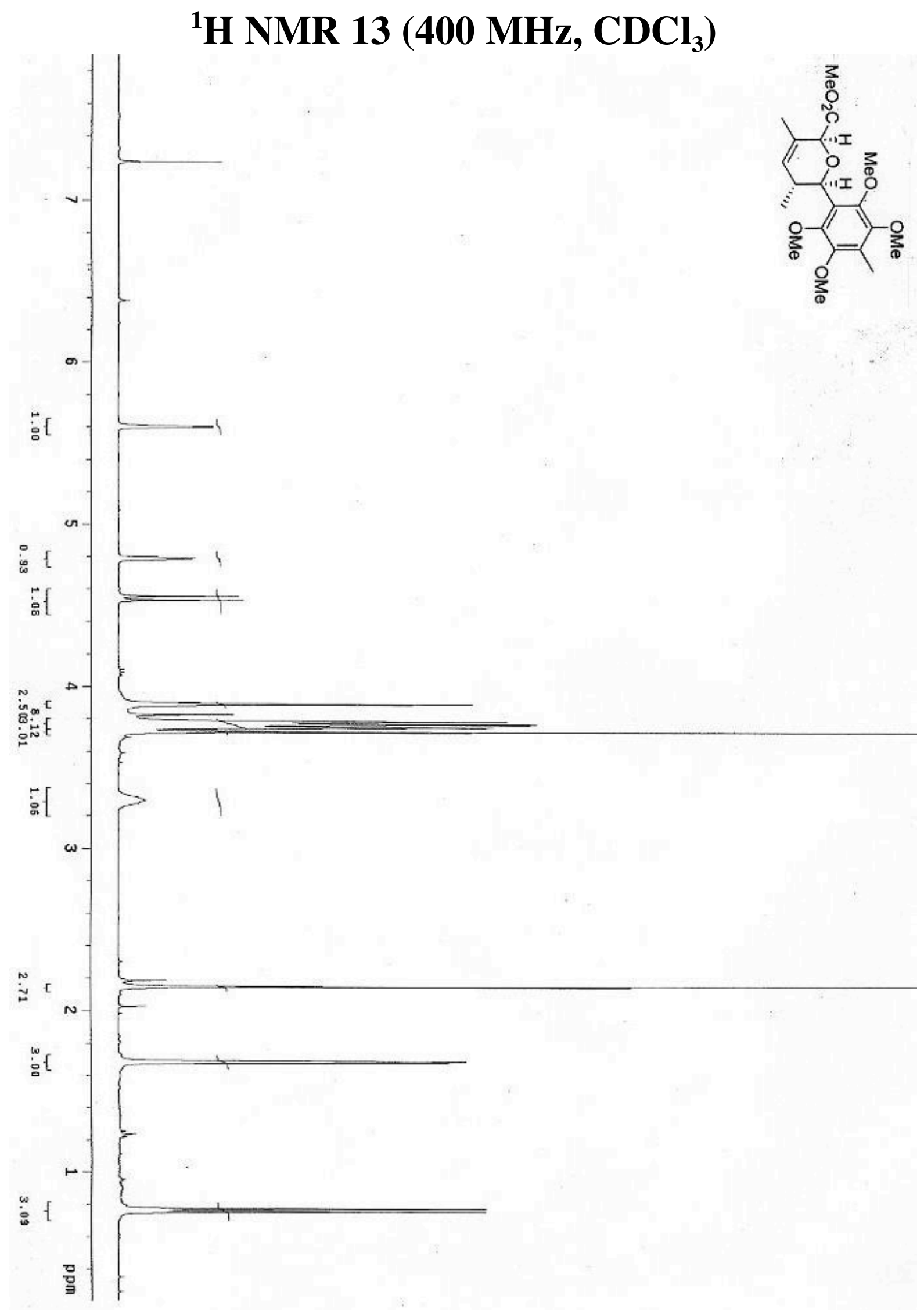




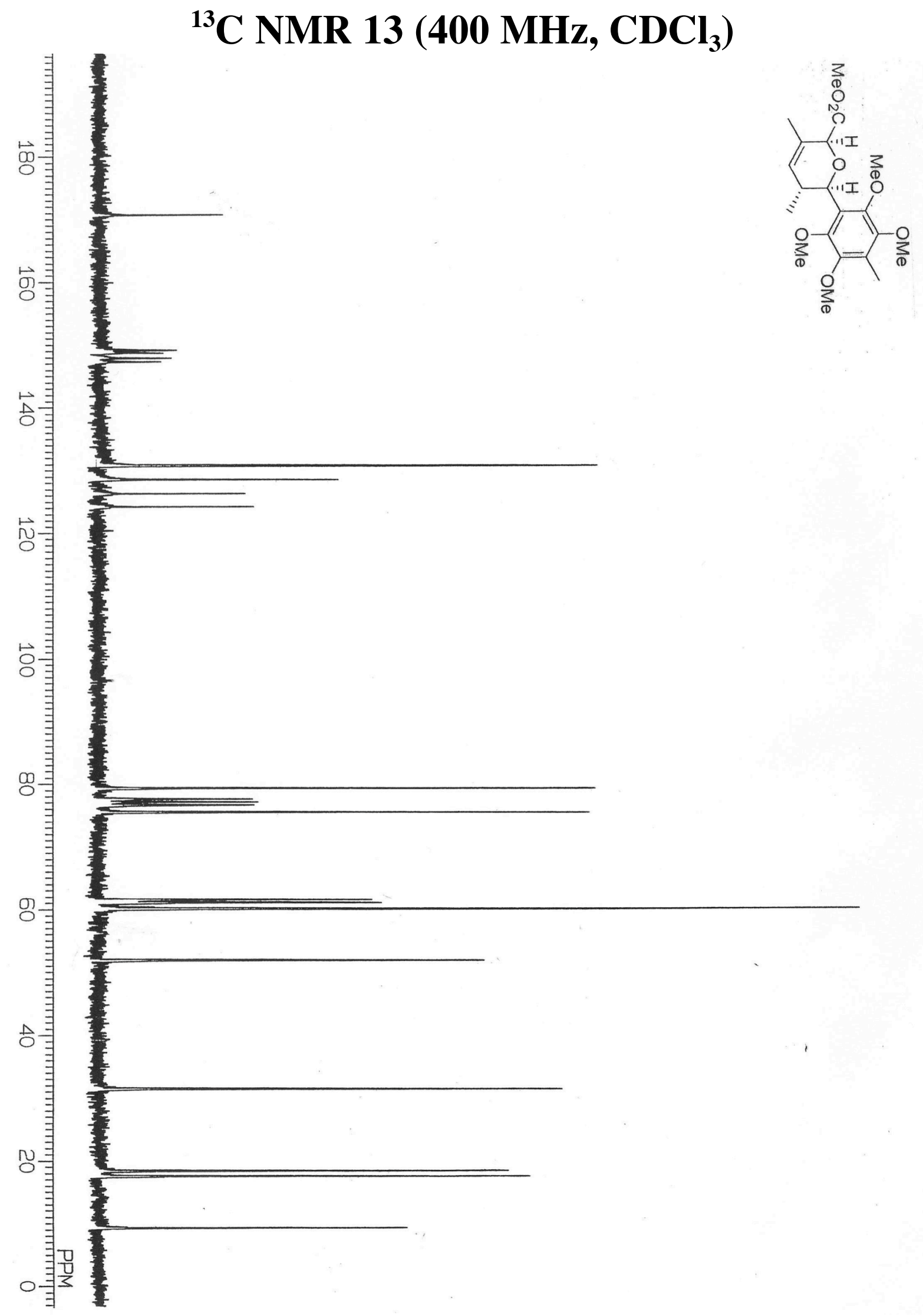




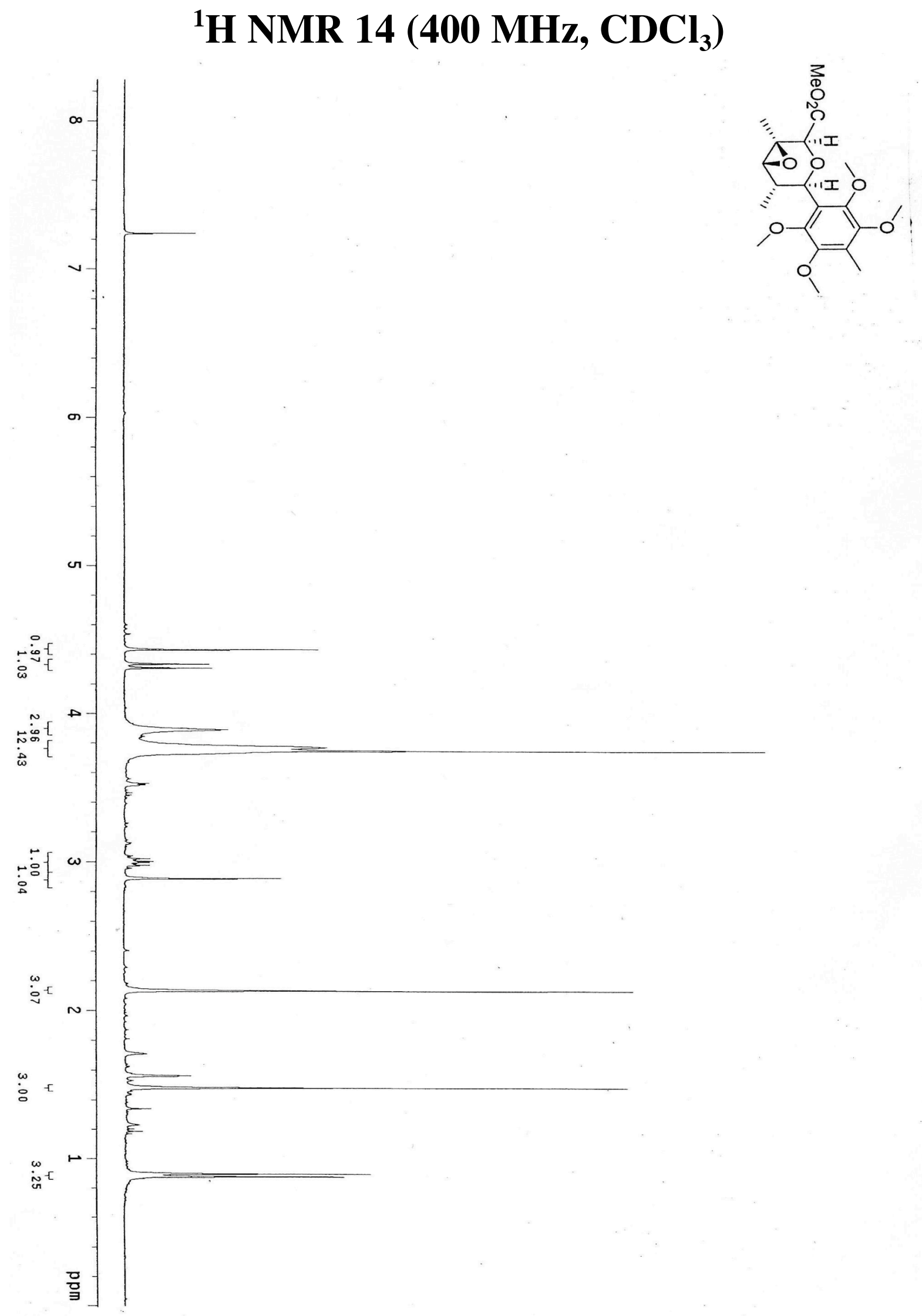




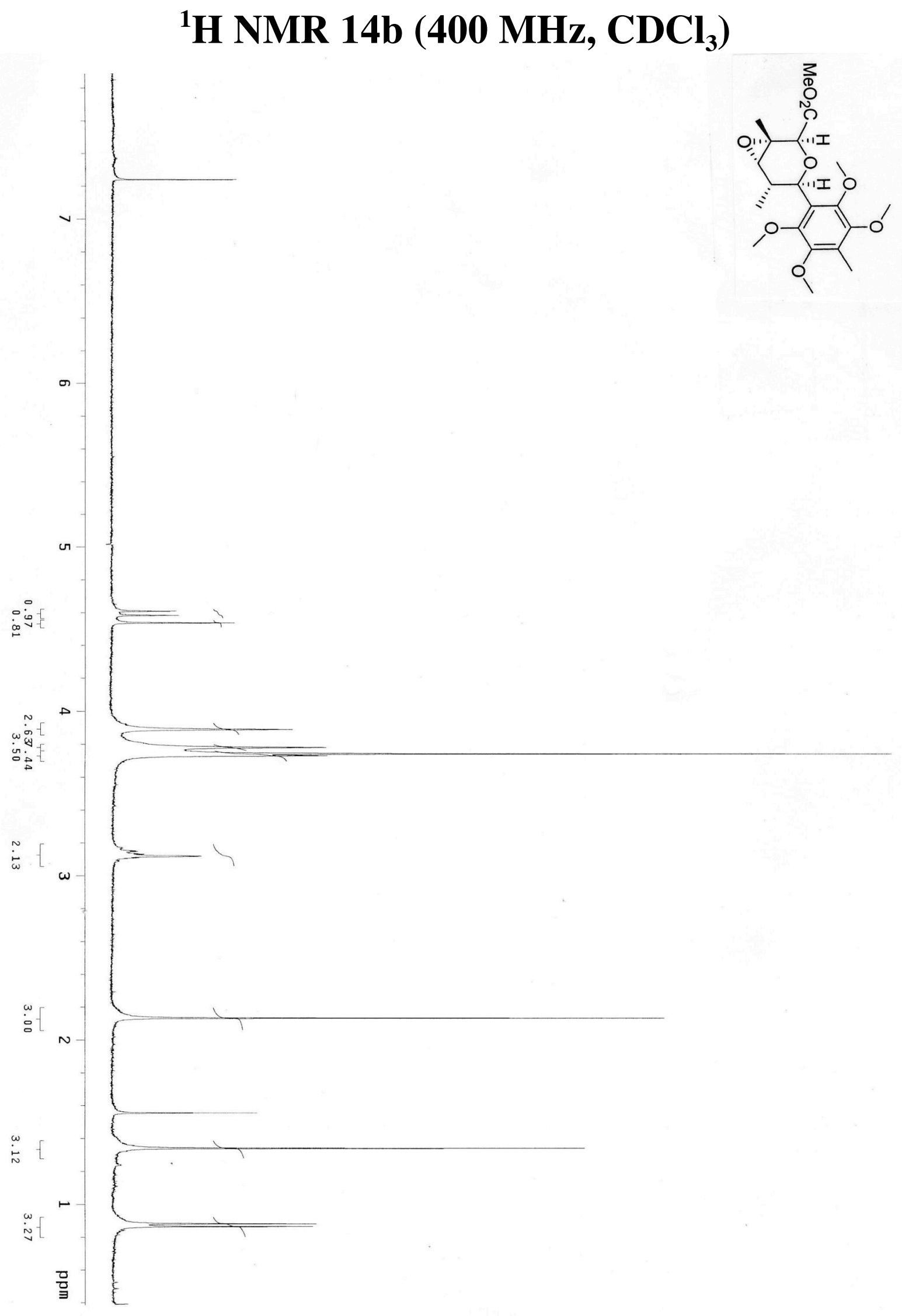

SI - 44 


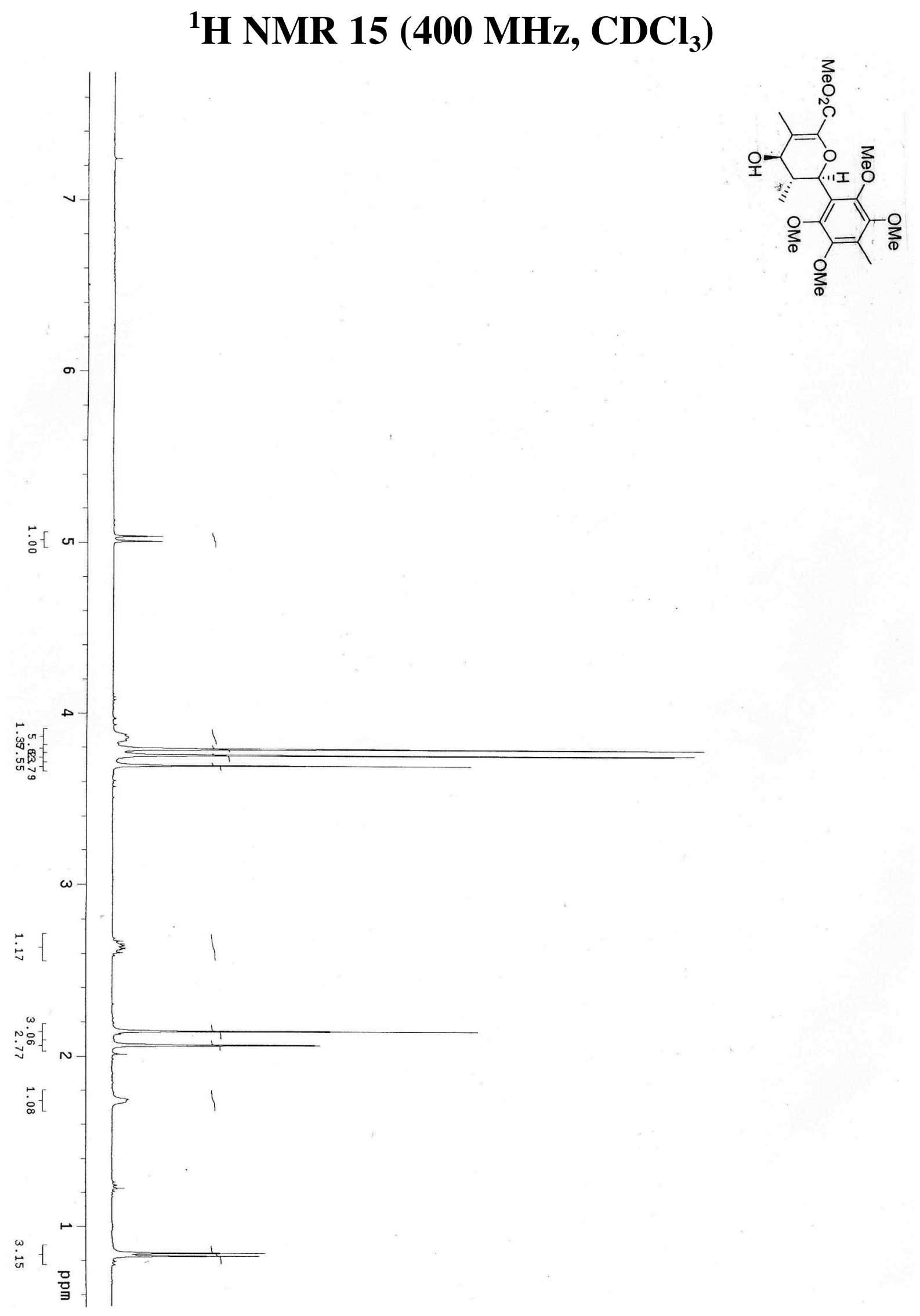

SI - 45 


\section{${ }^{13} \mathrm{C}$ NMR 15 (400 MHz, $\left.\mathrm{CDCl}_{3}\right)$}

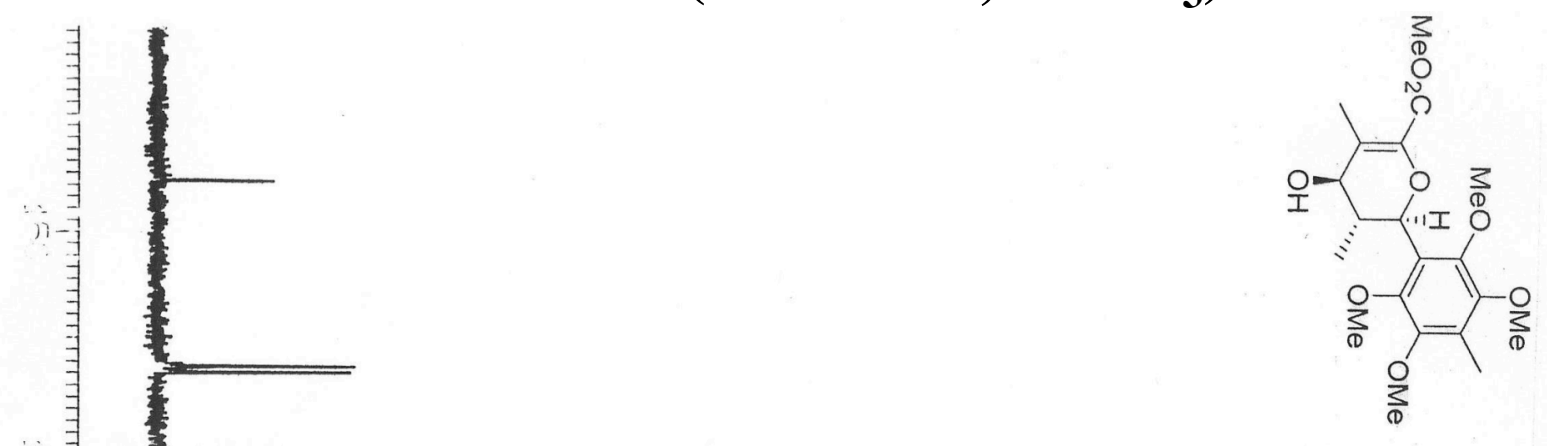

眥 


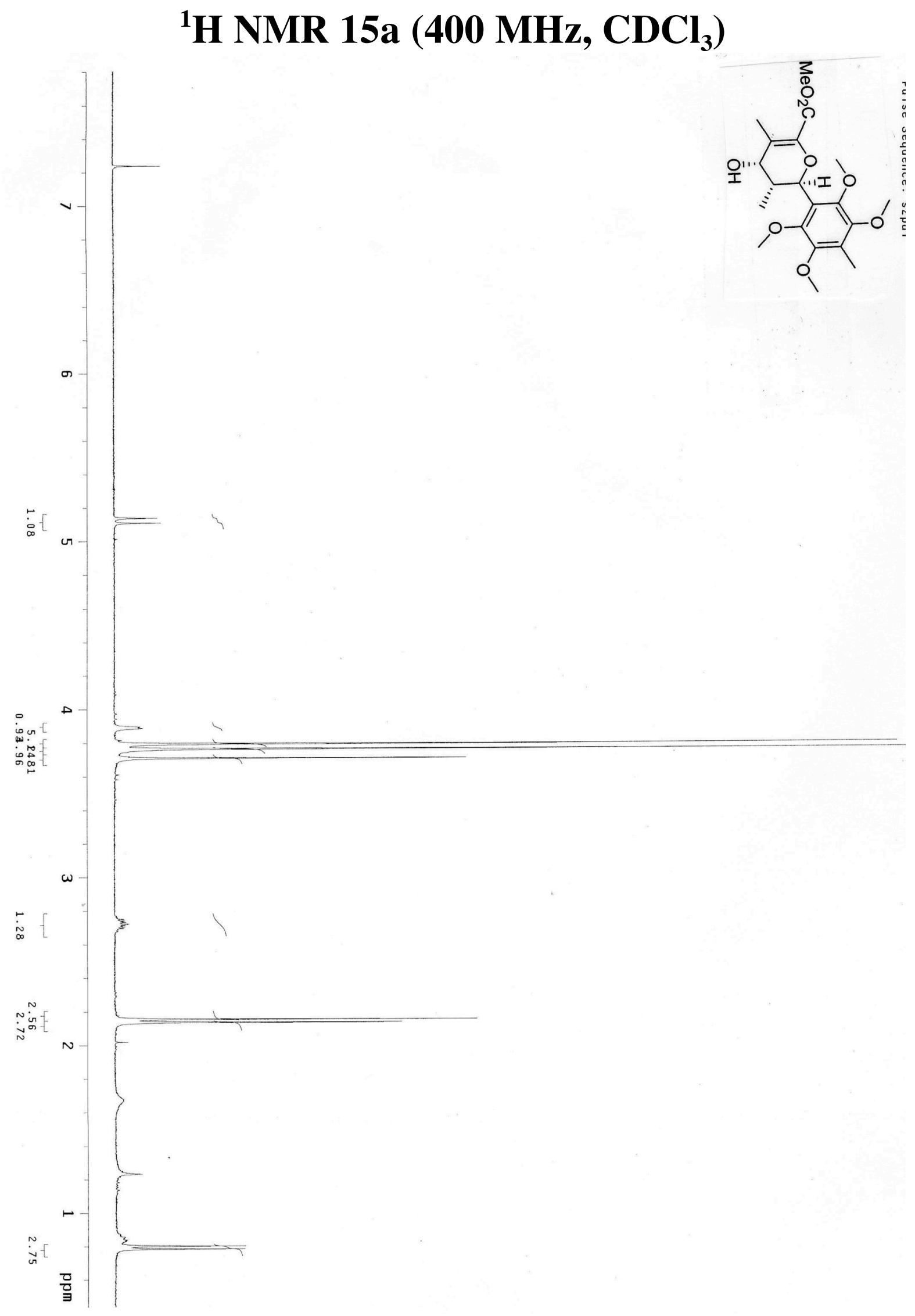




\section{${ }^{13} \mathrm{C}$ NMR $15 a\left(400 \mathrm{MHz}, \mathrm{CDCl}_{3}\right)$}

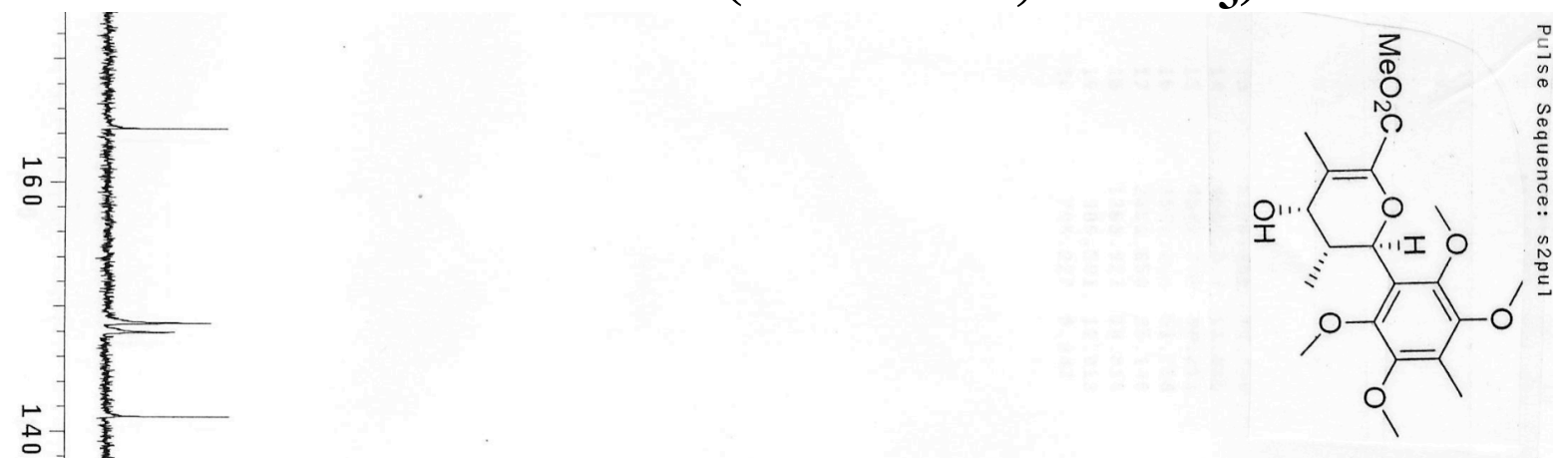

椋

a

g

:

ñ

妾

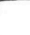

$=$

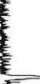

-

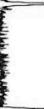

$\therefore$

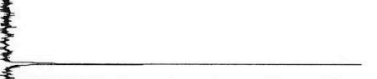

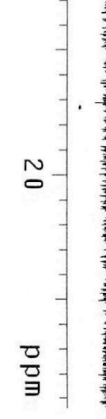

SI - 48 


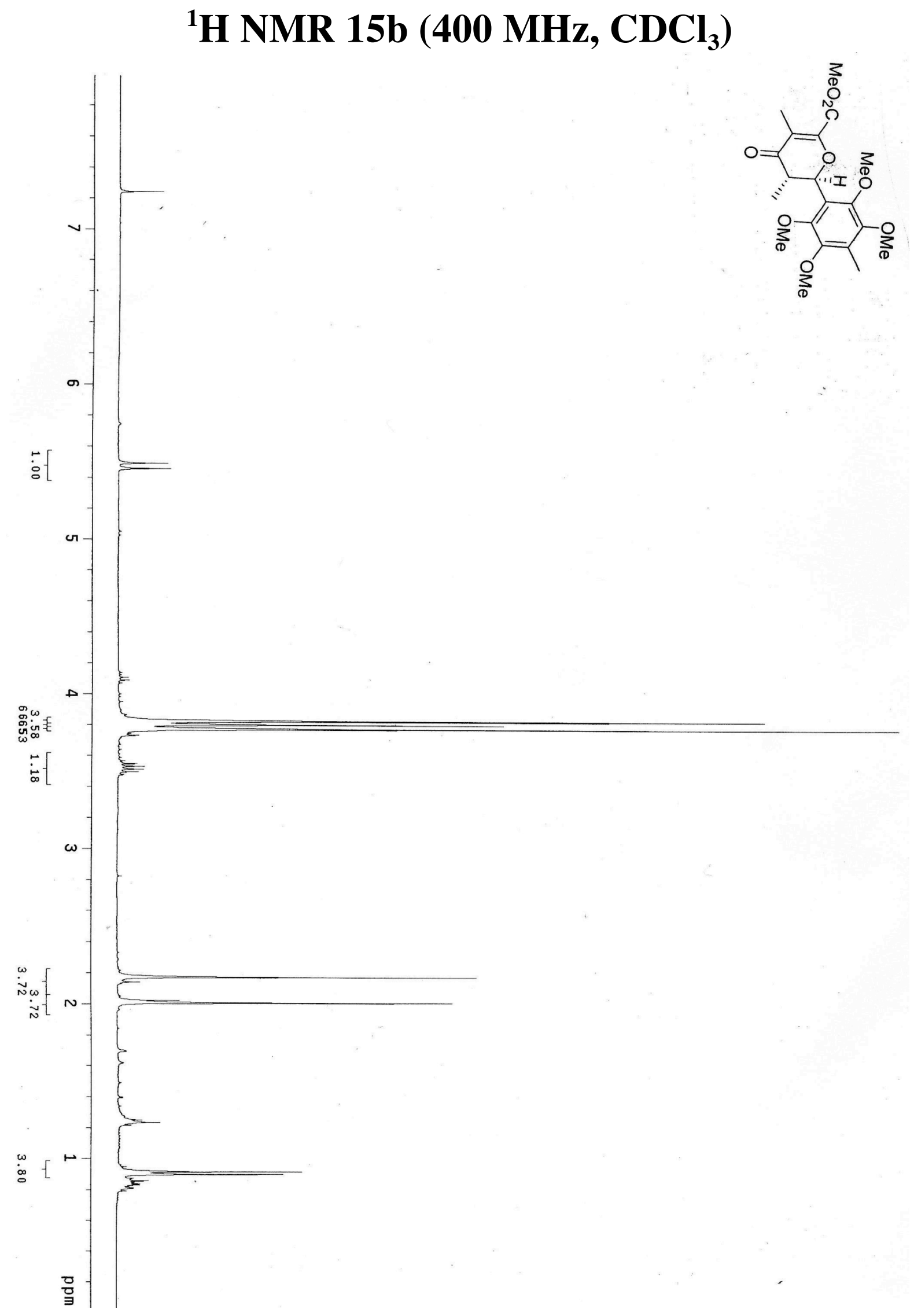

SI - 49 


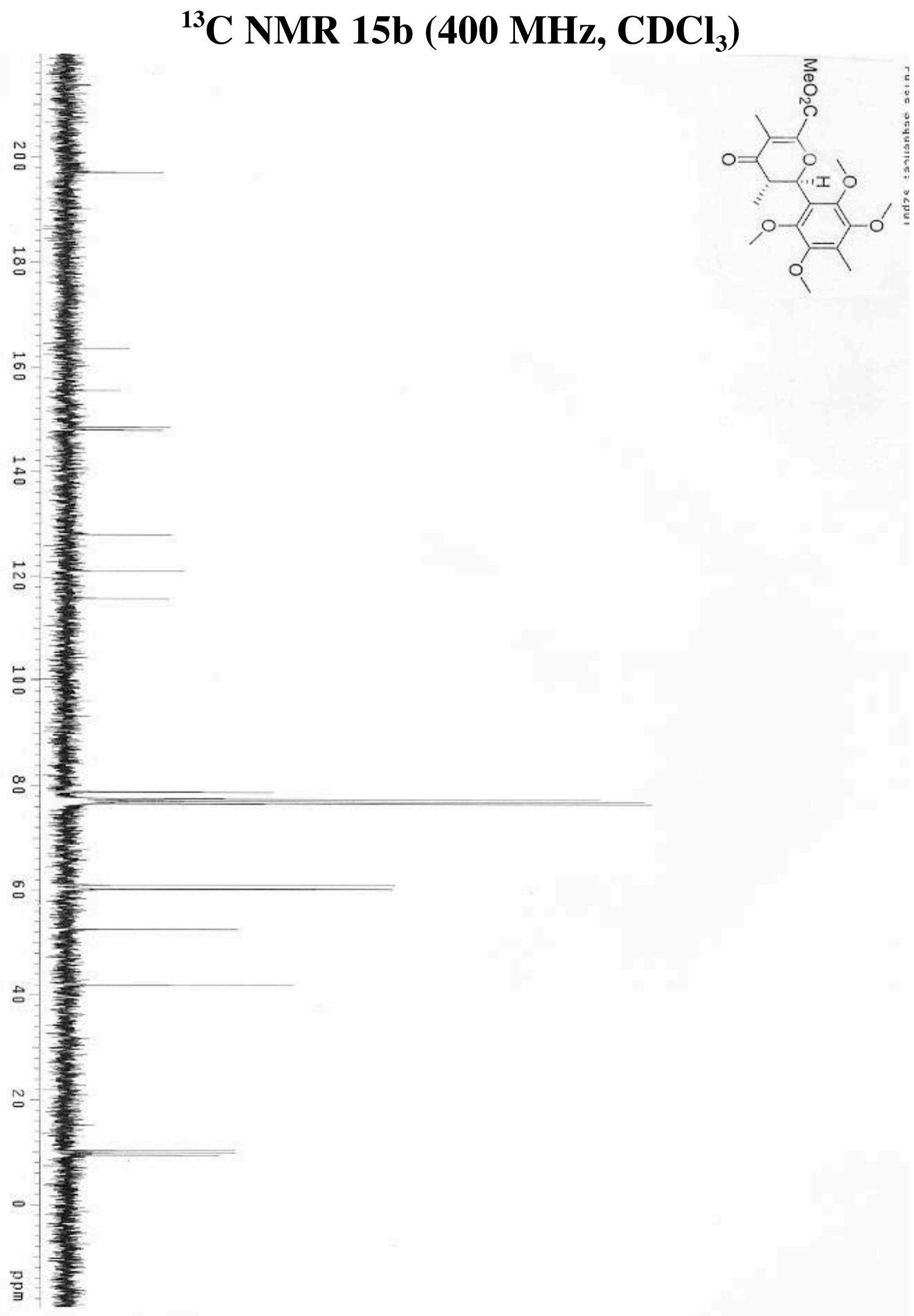

SI - 50 


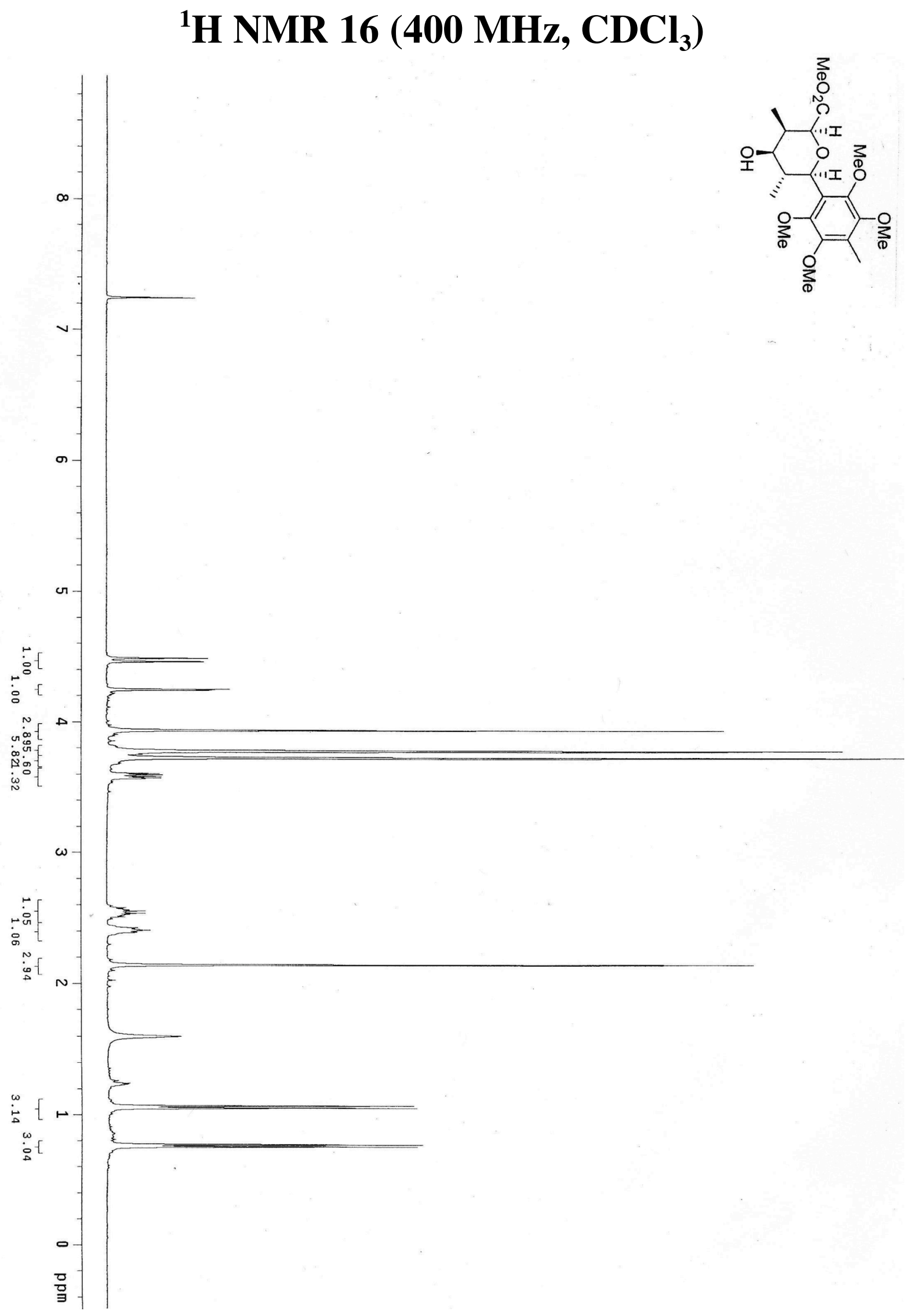




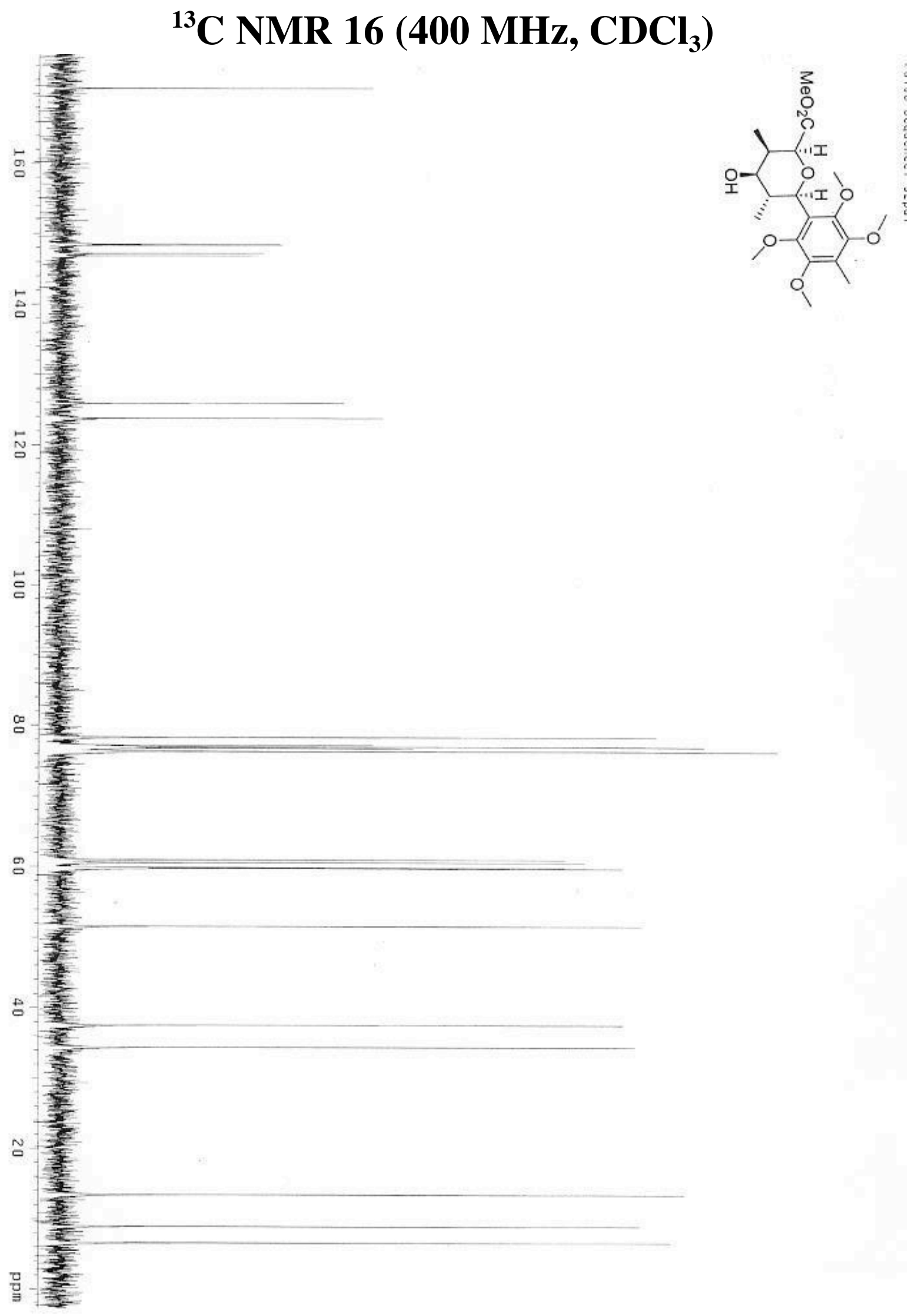

SI - 52 


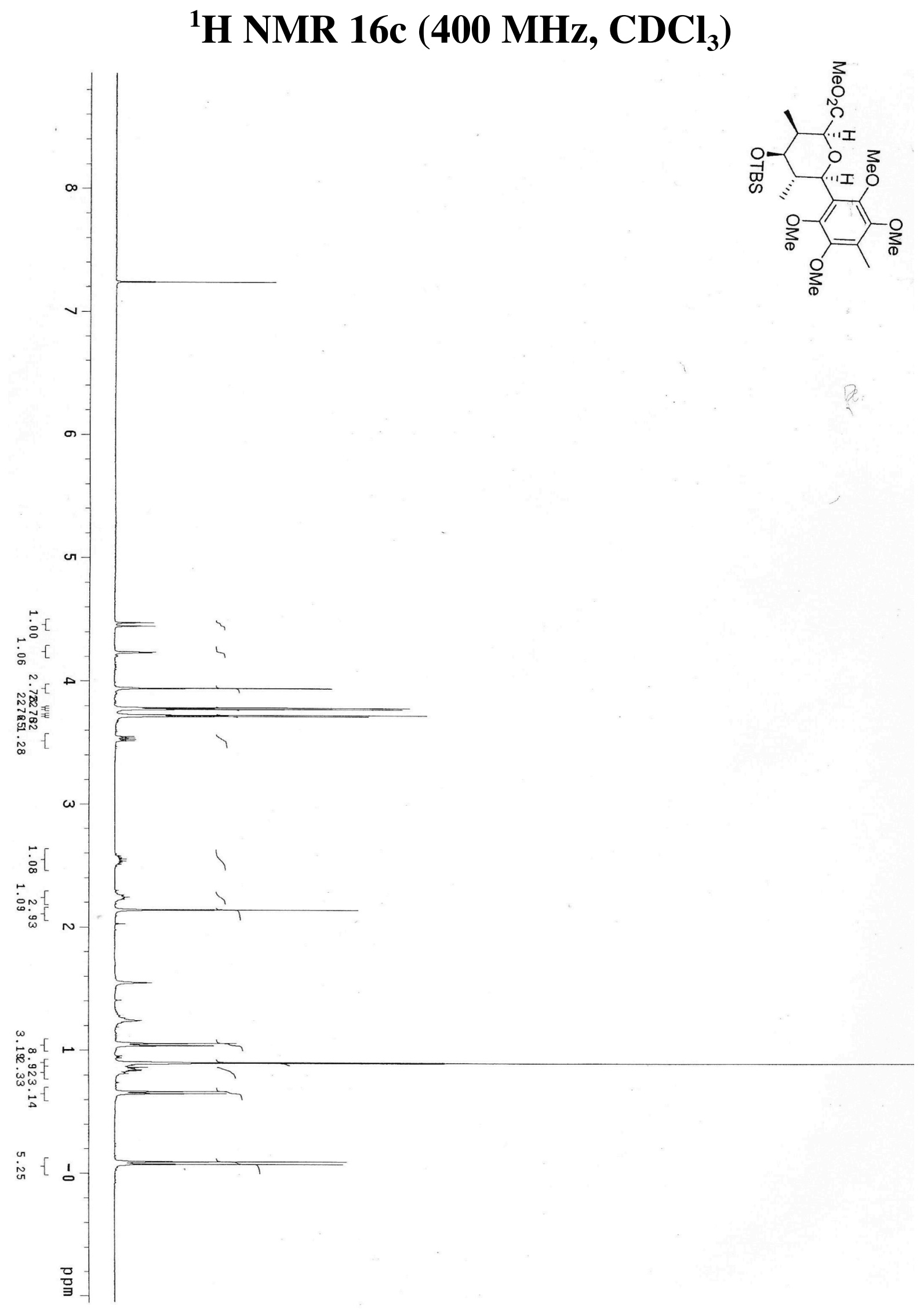

SI - 53 


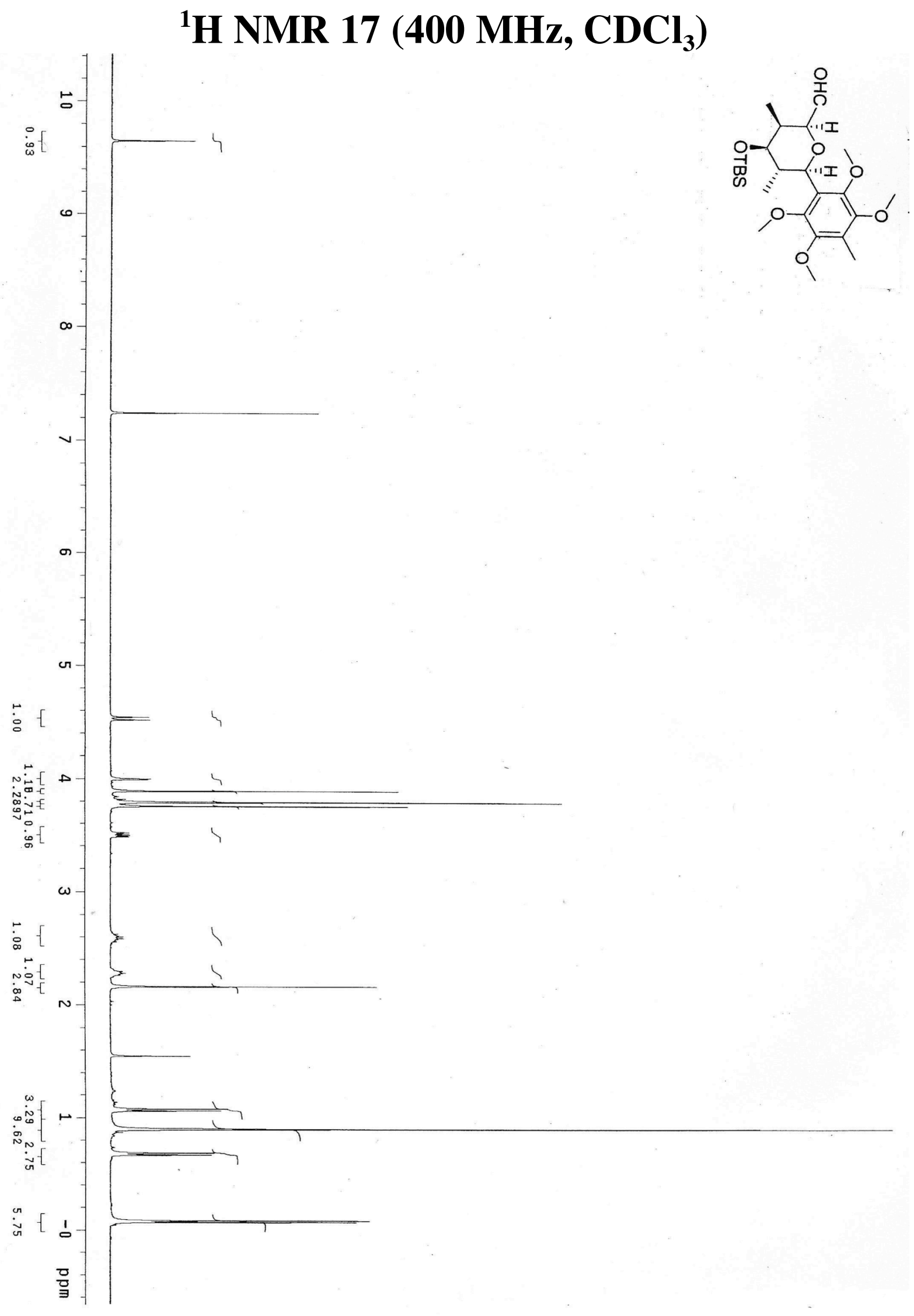




\section{${ }^{13} \mathrm{C}$ NMR 17 (400 MHz, $\mathrm{CDCl}_{3}$ )}

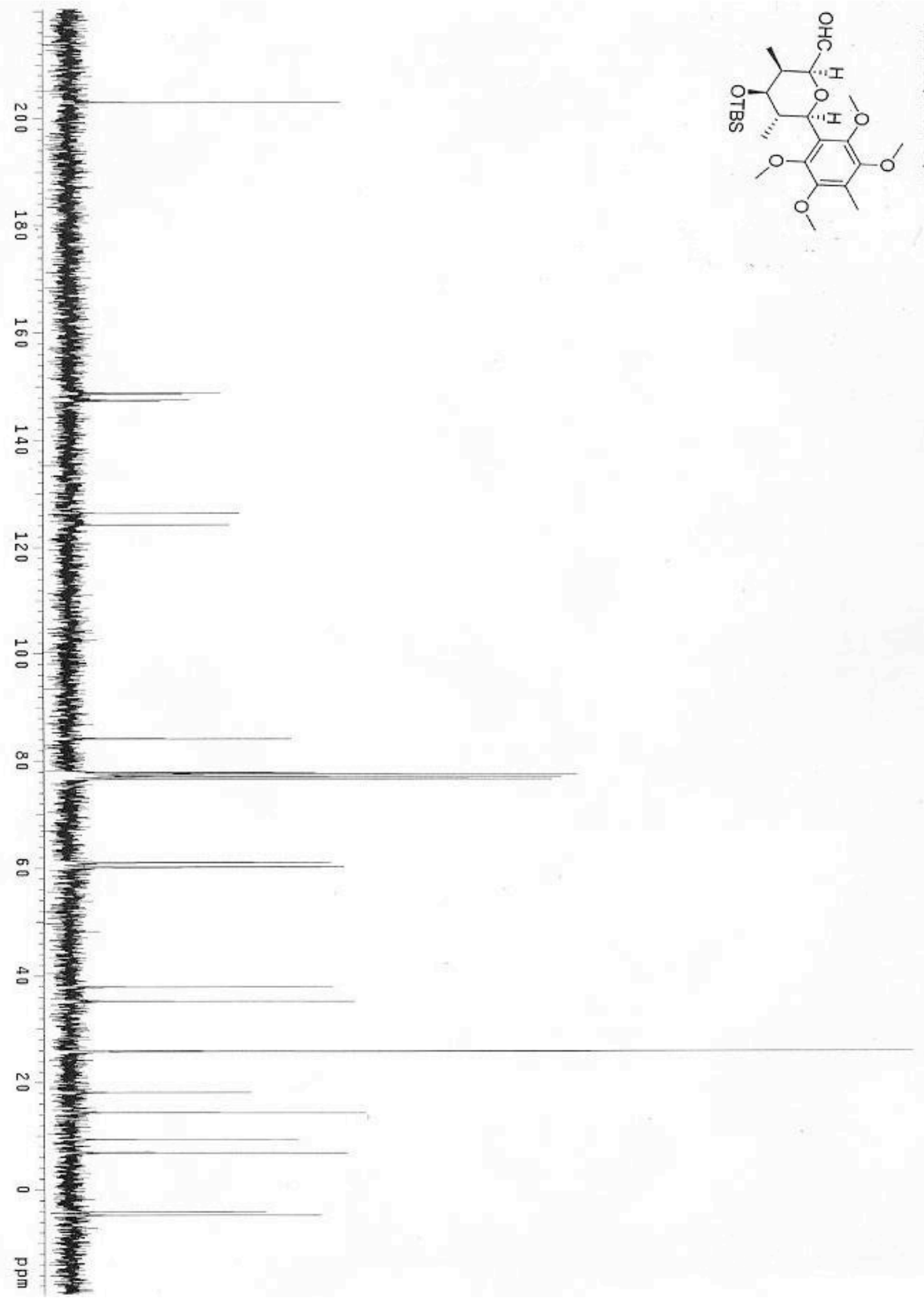

